\title{
Enhanced bentonites for containment of inorganic waste leachates by GCLs
}

\author{
J. Scalia IV ${ }^{1}$, G. L. Bohnhoff ${ }^{2}$, C. D. Shackelford ${ }^{3}$, C. H. Benson ${ }^{4}$, K. M. Sample-Lord ${ }^{5}$, \\ M. A. Malusis ${ }^{6}$ and W. J. Likos ${ }^{7}$ \\ ${ }^{1}$ Assistant Professor, Civil \& Environmental Engineering, Colorado State University, Fort Collins, \\ CO, USA, E-mail: joseph.scalia@colostate.edu (corresponding author) \\ ${ }^{2}$ Assistant Professor, Civil \& Environmental Engineering, University of Wisconsin-Platteville, Platteville, \\ WI, USA, E-mail: bohnhoffg@uwplatt.edu \\ ${ }^{3}$ Professor \& Head, Civil \& Environmental Engineering, Colorado State University, Fort Collins, \\ CO, USA,E-mail: shackel@engr.colostate.edu \\ ${ }^{4}$ Dean, School of Engineering, University of Virginia, Charlottesville, VA, USA, \\ E-mail: chbenson@virginia.edu \\ ${ }^{5}$ Assistant Professor, Civil \& Environmental Engineering, Villanova University, Villanova, PA, USA, \\ E-mail: kristin.sample-lord@villanova.edu \\ ${ }^{6}$ Professor, Civil \& Environmental Engineering, Bucknell University, Lewisburg, PA, USA, \\ E-mail:mam028@bucknell.edu \\ ${ }^{7}$ Professor \& Chair, Geological Engineering, University of Wisconsin-Madison, Madison, WI, USA, \\ E-mail: likos@wisc.edu
}

Received 10 July 2017, revised 09 January 2018, accepted 21 April 2018, published 02 July 2018

\begin{abstract}
The sensitivity of sodium bentonite (Na-B) to adverse chemical interactions has spurred development of enhanced bentonites (EBs) for geosynthetic clay liners (GCLs) that provide superior properties for containment systems. EB-GCLs are engineered to control contaminant transport by maintaining low hydraulic conductivity $(k)$ when exposed to solutions with high ionic strength, a preponderance of divalent cations, and/or extreme $\mathrm{pH}(<2$ and $>12)$. An overview of current EB-GCL technologies is provided. Engineering properties, including $k$, the effective diffusion coefficient $\left(D^{*}\right)$, and the membrane or chemico-osmotic efficiency coefficient $(\omega)$, are summarized for EBs and compared to properties of conventional Na-B. Applicability of indicator parameters currently used to assess GCLs containing Na-B (swell index, fluid loss, and liquid limit) is evaluated for EBs. Mechanisms proven or postulated to influence the behavior of EBs are presented and discussed. EBs generally have superior transport properties (lower $k$, lower $D^{*}$, higher $\omega$ ) in elevated concentration solutions, although some bentonites amended with proprietary additives (broadly termed contaminant resistant clays, or CRCs) have been found to be similar or inferior to Na-B. Compatibility tests conducted with containment liquids are necessary to assess the transport properties of EB-GCLs for site-specific applications.
\end{abstract}

KEYWORDS: Geosynthetics, Bentonite, Enhanced bentonite, Geosynthetic clay liner

REFERENCE: Scalia IV, J., Bohnhoff, G. L., Shackelford, C. D., Benson, C. H., Sample-Lord, K. M., Malusis, M. A. and Likos, W. J. (2018). Enhanced bentonites for containment of inorganic waste leachates by GCLs. Geosynthetics International, 25, No. 4, 392-411. [https://doi.org/10.1680/ jgein.18.00024]

\section{INTRODUCTION}

Geosynthetic clay liners (GCLs) consist of a layer of granular or powdered sodium bentonite (Na-B) approximately $7-10 \mathrm{~mm}$ thick sandwiched between two geotextiles. In some cases, a geofilm or geomembrane is laminated to one side. GCLs can be low hydraulic conductivity barriers, and are often used in lieu of thicker compacted clay liners in environmental containment applications (e.g. solid waste landfills, waste impoundments, lagoons, tailings impoundments). The effectiveness of GCLs in containment applications has been demonstrated for systems with low ionic strength $(I)$ solutions and leachates (Shackelford et al. 2000; Jo et al. 2004; Chen et al. 2018), such as municipal solid waste leachate (Bradshaw and Benson 2014). However, GCLs are less effective barriers (particularly under low confining stresses) to aggressive liquids, such as brines and/or 
solutions of extreme $\mathrm{pH}(2>\mathrm{pH}>12)$ that may exist in some containment applications, such as energy production and mining (Benson et al. 2010a; Bouazza 2010; Gates and Bouazza 2010; Hornsey et al. 2010; Bouazza and Gates 2014; Chen et al. 2014, 2018; Tian et al. 2016a).

To expand the portfolio of solutions that can be contained by GCLs, the bentonite component of GCLs can be chemically modified or blended with organic molecules or polymers (Onikata et al. 1996; Onikata et al. 1999; Lin et al. 2000; Trauger and Darlington 2000; Schroeder et al. 2001; Ashmawy et al. 2002; Kolstad et al. 2004b; McRory and Ashmawy 2005; Mazzieri and Pasqualini 2006; Katsumi et al. 2008; Benson et al. 2010a, 2010b; Di Emidio et al. 2010; Mazzieri et al. 2010a, 2010b; Shackelford et al. 2010; Di Emidio et al. 2011; Mazzieri and Pasqualini 2011; Scalia et al. 2011; Bohnhoff et al. 2013; Benson et al. 2014; Bohnhoff and Shackelford 2014; De Camillis et al. 2014; Scalia and Benson 2014; Scalia et al. 2014; Arndt et al. 2015; Athanassopoulos et al. 2015; Di Emidio et al. 2015; Janssen et al. 2015; Mazzieri and Di Emidio 2015; Tian and Benson 2015; Bohnhoff et al. 2016; De Camillis et al. 2016a, 2016b; Fehervari et al. 2016; Gates et al. 2016; Goldenberg and Reddy 2016; Malusis and Daniyarov 2016; Scalia and Benson 2016; Tian et al. 2016a, 2016b, 2017). These engineered materials, termed herein as enhanced bentonites (EBs), are at the forefront of environmental containment applications, and increasingly are being adopted in practice to contain aggressive leachates (e.g. fracking brines, coal combustion products, mine waste leachates). Current research into the use of EBs has largely resulted from an understanding of the limitations of GCLs containing unamended Na-B, concurrent with an increased need for barrier systems to contain high concentration and extreme $\mathrm{pH}$ solutions (e.g. in energy production and mining applications). If correctly designed, selected, manufactured, and constructed, GCLs containing EBs (EB-GCLs) have the potential to provide superior barrier performance.

This paper provides a review of EB-GCLs developed to minimize contaminant transport in environmental containment applications. The primary focus is the hydraulic conductivity, $k$, of the EB-GCLs subjected to a variety of permeant liquids. However, achieving low $k$ for chemical containment barriers has been shown to be a necessary but not sufficient condition for preventing unacceptable releases of contaminants to the surrounding environment (Shackelford 2014). For example, at low $k$ $\left(<\sim 5 \times 10^{-10} \mathrm{~m} / \mathrm{s}\right)$, diffusion of contaminants can be a significant if not dominant contaminant transport process. Also, relatively recent evidence indicates that bentonite-based barriers such as GCLs behave as semipermeable membranes that restrict the migration of aqueous-phase solutes, which can enhance the containment performance of the barriers (Shackelford 2013; Shackelford and Scalia 2016). For these reasons, a secondary focus is the effective diffusion coefficient, $D^{*}$, and membrane or chemico-osmotic efficiency coefficient, $\omega$, of EB-GCLs relative to those for traditional GCLs.
A summary of $k, D^{*}$, and $\omega$ for EB-GCLs is provided and compared to those of traditional GCLs. Applicability of indicator parameters (e.g. swell index, fluid loss, and liquid limit) used to assess the $k$ of EB-GCLs is also evaluated. Mechanisms underlying, or hypothesized to underlie, the behavior of EB-GCLs are presented and discussed.

\section{BACKGROUND}

\subsection{Bentonite}

Most GCLs employed rely on Na-B due to the low $k$ of $\mathrm{Na}-\mathrm{B}$ to water and dilute aqueous solutions (Shackelford et al. 2000; Jo et al. 2001, 2005; Kolstad et al. 2004a; Lee and Shackelford 2005a). The mechanical and hydraulic behavior of bentonite is governed largely by the amount of montmorillonite clay mineral comprising the bentonite (Grim 1968). The effectiveness of $\mathrm{Na}-\mathrm{B}$ as a barrier for chemical containment applications depends on the osmotic adsorption of water molecules in the montmorillonite interlayers that is manifest as swell. In cases where the swelling is constrained, such as within a GCL, the swelling reduces the size of the pores available for liquid flow and solute transport (McBride 1994; Jo et al. 2006; Scalia and Benson 2011).

A schematic illustrating the interrelationship of interlayer expansion and flow and transport through a GCL containing Na-B is shown in Figures 1a-1d. As manufactured, GCLs consist of dry granules of crushed and milled bentonite (Figure 1a). Often, these dry granules have aggregate size distributions similar to sands (either SP or SW-SC based on the Unified Soil Classification System, ASTM D2487) and, thus, would be permeable if the bentonite did not hydrate and swell (Shackelford et al. 2000). Bentonite granules consist of aggregates of montmorillonite particles, also referred to as quasicrystals, or assemblages of montmorillonite lamellae with a similar orientation (Quirk and Aylmore 1971), and accessory minerals (Shan and Daniel 1991; Shackelford et al. 2000; Jo et al. 2001, 2005; Kolstad et al. 2004a; Lee and Shackelford 2005a), as conceptually illustrated in Figures $1 \mathrm{~b}$ and $1 \mathrm{c}$. These schematics are a simplification of the variety of structural units that exist in bentonite (Salles et al. 2008). When bentonite is wetted with water, external particle surfaces are wetted, followed by interlamellar surfaces and cations (Norrish 1954; Salles et al. 2008). This initial hydration process results in stepwise increases in interlamellar spacing from interlamellar distances of approximately $1.0 \mathrm{~nm}$ (dry; this distance includes the $0.96-\mathrm{nm}$ thick montmorillonite lamellae) to $2.1-2.2 \mathrm{~nm}$ (four layers of interlamellar water molecules; Saiyouri et al. 2004), commonly referred to as crystalline swelling (Norrish 1954; Norrish and Quirk 1954). In Na-B (but not calcium bentonite, $\mathrm{Ca}-\mathrm{B})$, further wetting, beyond the point where crystalline swelling is completed, results in osmotic adsorption of water molecules within and around the montmorillonite particles (Norrish 1954; Tessier and Pedro 1982; Ben Rhaiem et al. 1987; Tessier 1990; Salles et al. 2008; Arndt et al. 2017; Figures 1c and 1d). 


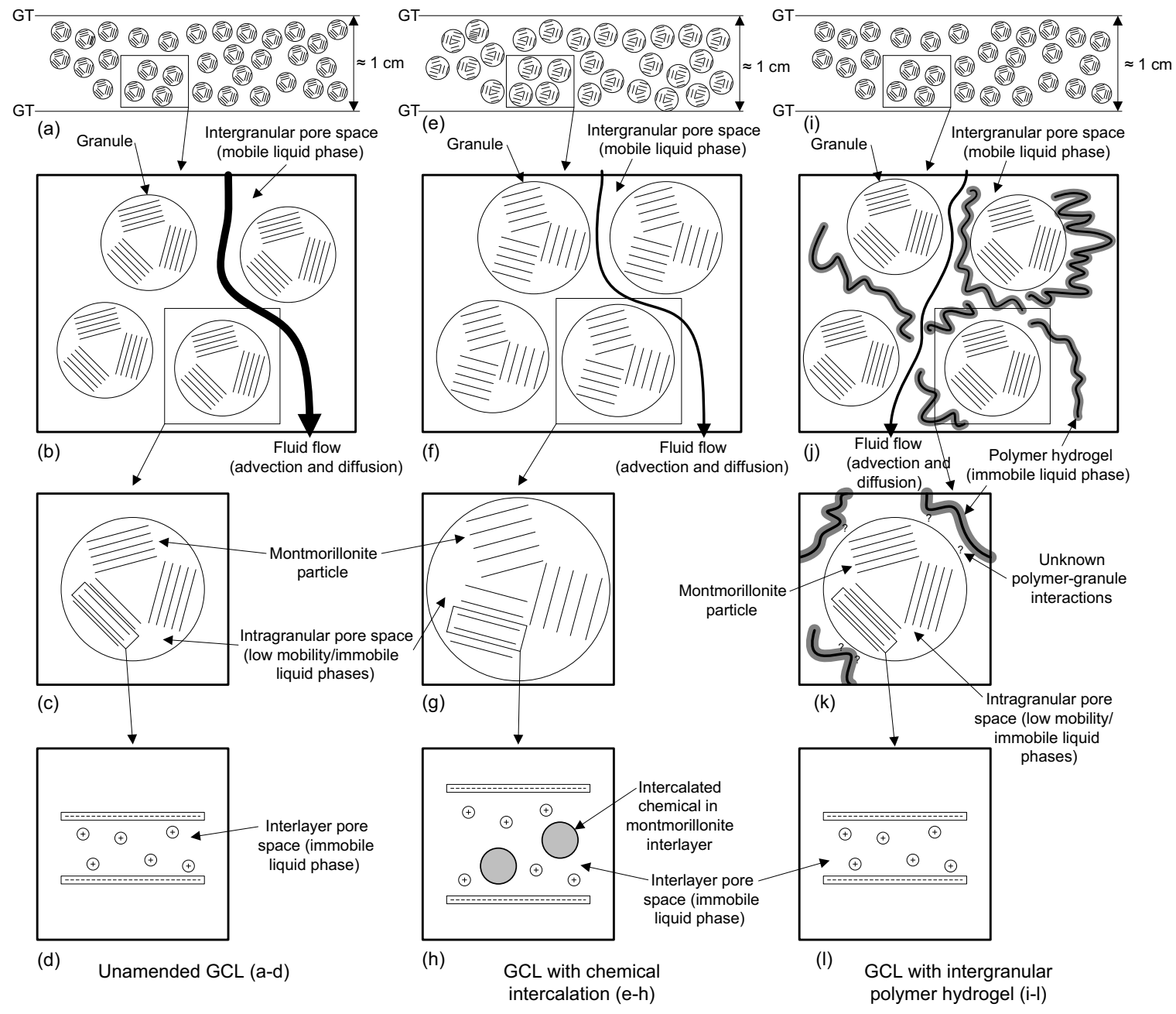

Figure 1. Schematic representation of GCL containing Na-Bentonite (a), GCL containing bentonite modified by chemical intercalation (e), and GCL containing bentonite modified by intergranular polymer hydrogel (i), flow and transport pathway in the intergranular $(b, f)$ and, when present, inter-hydrogel pores ( $j$ ) of bentonite, low mobility and immobile liquid phases in interparticle pore space that provides minimal contribution to flow and transport $(\mathrm{c}, \mathrm{g}, \mathrm{k})$, and immobile liquid phase in interlayer particle space with (d, l) and without (h) intercalation that does not contribute to flow and transport. Panels a-d after Jo et al. (2006)

These yield a less hydraulically mobile liquid phase (relative to non-adsorbed porewater) in both the interlayer (Mesri and Olson 1971; Kolstad et al. 2004a; Scalia and Benson 2011; Figure 1d) and the volume immediately surrounding the montmorillonite particles within the intragranular (interparticle) pore space (Salles et al. 2008, 2009, 2010; Likos and Wayllace 2010; Figure 1b). Spontaneous delamination of lamellae from montmorillonite particles occurs concurrently with osmotic swelling (not shown in Figure 1 for simplicity), further increasing the tortuosity of intragranular pores (Shomer and Mingelgrin 1978; Segad et al. 2012). If swelling and delamination are sufficient, as is the case within a GCL when osmotic swelling occurs, the dominant conduits for mobile liquid - that is, intergranular pores (Figure 1b) become limited as the granules swell together. In such cases, the primary pathways for liquid flow and solute transport are relegated to narrow and tortuous intragranular pores (Figure 1c), which results in low $k$ (Jo et al. 2001, 2005; Kolstad et al. 2004a; Meer and Benson 2007; Scalia and Benson 2011), low rates of diffusion (Malusis and Shackelford 2002a; Shackelford and Lee 2003;
Malusis et al. 2015), and solute restriction or semipermeable membrane behavior (Malusis and Shackelford 2002b; Kang and Shackelford 2011; Shackelford 2013; Sample-Lord and Shackelford 2014, 2018; Shackelford et al. 2016).

Osmotic swelling in montmorillonite occurs only when monovalent cations, such as $\mathrm{Na}^{+}$, dominate the exchange complex - that is, the collection of exchangeable cations satisfying the negative structural charge of montmorillonite (McBride 1994). If multivalent cations (i.e. charge $\geq 2^{+}$) dominate the exchange complex prior to hydration, osmotic swelling does not occur, resulting in an open intergranular pore structure and a much higher $k$ (Jo et al. 2001, 2005; Kolstad et al. 2004a; Meer and Benson 2007; Katsumi et al. 2008; Bouazza and Bowders 2010; Scalia and Benson 2011; Tian et al. 2016a, 2016b; Chen et al. 2018). Solutions with high ionic strength, including homo-ionic monovalent solutions, also limit or eliminate osmotic swell by mass action effects (McBride 1994), resulting in higher $k$.

Flow and transport through GCLs is governed by the $k$ of the bentonite. Hydraulic conductivities on the order 
of $1-3 \times 10^{-11} \mathrm{~m} / \mathrm{s}$ are typical for GCLs permeated at low effective stress with dilute permeant solutions (Shackelford et al. 2000; Jo et al. 2001, 2005; Kolstad et al. 2004a). However, quantitative definitions for low effective stress and dilute permeant solution are difficult to establish for GCLs, because $k$ depends on the specific chemical and physical properties of both the GCL and the permeant solution (Shackelford et al. 2000; Jo et al. 2001; Kolstad et al. 2004a; Lee and Shackelford 2005a). In chemical containment applications, a maximum $k$ of $5 \times 10^{-11} \mathrm{~m} / \mathrm{s}$ is often required for GCLs (e.g. refer to the GRI-GCL3 Specification for GCLs, GI 2016). For Na-B to yield $k \leq 5 \times 10^{-11} \mathrm{~m} / \mathrm{s}$, the Na-B must be permeated under conditions that produce or maintain a high degree of osmotic swelling. These conditions include permeation with a low ionic strength permeant solution as determined by compatibility experiments (Kolstad et al. 2004a). If the permeant liquid contains multivalent cations, prevention of wet-dry cycling after permeation is also necessary (Meer and Benson 2007; Benson and Meer 2009; Scalia and Benson 2011).

The ionic strength at which a GCL has high $k$ (e.g. $\geq 5 \times 10^{-11} \mathrm{~m} / \mathrm{s}$ ) depends on bentonite quality, which is a function of the fraction of montmorillonite comprising the mineralogy, the bound cation composition, the concentration and composition of soluble salts, and the bentonite aggregate size distribution (Lee and Shackelford 2005a), and physical conditions (e.g. effective stress, degree of consolidation, degree of saturation). At lower ionic strength $(<0.5 \mathrm{M})$, GCL $k$ also is influenced by the relative abundance or ratio of monovalentto-divalent cations, RMD, as defined by Kolstad et al. (2004a). For solutions with a given ionic strength, the $k$ of a GCL will generally increase with decreasing RMD. Kolstad et al. (2004a) found that solute concentration has the dominant influence on $k$ at higher ionic strength $(\geq 0.5 \mathrm{M})$ relative to $\mathrm{RMD}$.

Three index properties of the bentonite are commonly used as indicators for the $k$ of GCLs; that is, swell index (ASTM D5890), fluid loss (ASTM D5891), and liquid limit (ASTM D4318). These properties, when measured using deionized (DI) water, are used to screen bentonite quality. For example, the Geosynthetic Research Institute standard GRI-GCL3 (Rosin-Paumier et al. 2010; GI 2016) requires a minimum swell index of $24 \mathrm{ml} / 2 \mathrm{~g}$ and a maximum fluid loss of $18 \mathrm{ml}$ in DI water for bentonite in new GCLs. Index properties are also used to screen for hydraulic incompatibility (i.e. potential for $k \gg 5 \times 10^{-11} \mathrm{~m} / \mathrm{s}$ ) by testing with potential permeant solutions instead of DI water (Jo et al. 2001; Lee et al. 2005; Chung and Daniel 2008; Guyonnet et al. 2009; Liu et al. 2013). Index properties provide an indication of the $k$ and the potential for incompatibility between the bentonite and the permeant liquid. However, these properties do not capture all factors that can affect $k$, such as pore structure and void ratio (Lee et al. 2005). Thus, index properties are surrogates for measurement of $k$ (Lee et al. 2005; Katsumi et al. 2008; Guyonnet et al. 2009; Benson et al. 2010a, 2010b; Scalia et al. 2014).

\subsection{Enhanced bentonite}

Enhanced bentonites are intended to maintain low $k$ and sealing ability in applications where Na-B does not provide sufficient performance. Table 1 is a summary of EBs that have been reported in the literature for use, or potential use, in GCLs. Different names are given to bentonite modified by different additive(s), independent of additive concentration, and, in the case of denseprehydrated GCLs (DPH-GCLs), physical bentonite pretreatment (i.e. prehydration and vacuum extrusion). A brief description of the materials listed in Table 1 follows.

\subsubsection{Multi-swellable bentonite}

Multi-swelllable bentonite, or MSB, is created by mixing dry Na-B with a $15-45 \%$ (by mass) propylene carbonate (PC) solution (Onikata et al. 1996). During mixing, the PC is intercalated into the montmorillonite interlayer (e.g. see Figure 1h). The blended material is dried. Fehervari et al. (2016) developed a variant of MSB in which glycerol carbonate (GC; up to $50 \%$ by mass) is used instead of PC. The higher dielectric permittivity of GC relative to $\mathrm{PC}$, induces greater intercalation (Gates et al. 2016) and enhanced swelling in hyper-saline solutions (Fehervari et al. 2016). Because of the limited data for GC-amended GCLs, - that is, one $k$ test from Fehervari et al. (2016), GC-amended GCLs are included herein with MSB. Although Gates et al. (2016) demonstrate that other cyclic organic carbonates may provide a functional class of similar modifying agents, improved $k$ of these materials has not yet been demonstrated through testing. Fehervari et al. (2016) and Gates et al. (2016) demonstrate that increased loading of PC or GC results in enhanced swelling behavior of MSB relative to lower dosages. Thus, the dosage of PC, or GC, could be tailored to a specific engineering application based on required engineering properties.

\subsubsection{HYPER-clay}

HYPER-clay, or HC, is dry sodium or calcium bentonite modified by mixing with a solution containing $2-16 \%$ (by mass) sodium-carboxymethylcellulose (Na-CMC) (Di Emidio et al. 2010, 2011). During mixing, Na-CMC is hypothesized to intercalate into the montmorillonite interlayer. The blended material is oven dried and ground prior to use. Di Emidio et al. (2010, 2011, 2015), and De Camillis et al. (2014, 2016a, 2016b) demonstrate that increased CMC dosage corresponds to enhanced swelling and $k$ to seawater. Thus, similar to MSB, dosage of CMC could be tailored to a specific engineering application based on required engineering properties. A detailed analysis of the effect of $\mathrm{HC}$ dosage is not provided herein; the reader is refereed to Janssen et al. (2015) for additional information.

\subsubsection{Bentonite-polyacrylic-acid composite}

Bentonite-polyacrylic-acid composite, or BPC, is slurried Na-B modified by in-situ polymerization of acrylic acid to form sodium-polyacrylic acid (PAA) (Scalia et al. 2014). The same or similar materials 
Table 1. Enhanced bentonites used for geosynthetic clay liners (GCLs)

\begin{tabular}{|c|c|c|c|}
\hline Material & Additive(s) or modifications & $\begin{array}{l}\text { Flow and transport improvement } \\
\text { mechanisms }\end{array}$ & References \\
\hline $\begin{array}{l}\text { Multi-swellable bentonite } \\
\text { (MSB; \& similar) GCLs }\end{array}$ & Glycerol carbonate (GC) & $\begin{array}{l}\text { Swell enhancement by intercalated } \\
\text { molecule activating osmotic swelling }\end{array}$ & $\begin{array}{l}\text { Onikata et al. }(1996) \\
\text { Onikata et al. }(1999) \\
\text { Lin } \text { et al. }(2000) \\
\text { Mazzieri and Pasqualini (2006) } \\
\text { Katsumi et al. (2008) } \\
\text { Mazzieri } \text { et al. }(2010 \mathrm{a}) \\
\text { Fehervari et al. (2016) }\end{array}$ \\
\hline HYPER-clay (HC) GCLs & $\begin{array}{l}\text { Sodium-carboxymethyl } \\
\text { cellulose } \\
\text { (Na-CMC) }\end{array}$ & $\begin{array}{l}\text { Swell enhancement by intercalated } \\
\text { molecule activating osmotic swelling }\end{array}$ & $\begin{array}{l}\text { Di Emidio et al. }(2010) \\
\text { Di Emidio et al. }(2011) \\
\text { De Camillis et al. }(2014) \\
\text { Janssen } \text { et al. }(2015) \\
\text { Di Emidio et al. }(2015) \\
\text { De Camillis et al. (2016a, 2016b) }\end{array}$ \\
\hline $\begin{array}{l}\text { Dense-prehydrated GCLs } \\
\text { (DPH-GCLs) }\end{array}$ & $\begin{array}{l}\text { Na-CMC, sodium-polyacrylic } \\
\text { acid (PAA) }\end{array}$ & $\begin{array}{l}\text { Densification, prehydration, and unknown } \\
\text { chemical additive effects }\end{array}$ & $\begin{array}{l}\text { Schroeder } \text { et al. }(2001) \\
\text { Kolstad } \text { et al. }(2004 \mathrm{~b}) \\
\text { Katsumi } \text { et al. }(2008) \\
\text { Mazzieri } \text { et al. }(2010 \mathrm{~b}) \\
\text { Mazzieri and Pasqualini (2011) } \\
\text { Mazzieri and Di Emidio (2015) } \\
\text { Malusis and Daniyarov (2016) }\end{array}$ \\
\hline $\begin{array}{l}\text { Bentonite polyacrylic-acid } \\
\text { composite (BPC) GCLs }\end{array}$ & PAA & $\begin{array}{l}\text { Intergranular porosity clogging by } \\
\text { polymer hydrogels }\end{array}$ & $\begin{array}{l}\text { Trauger and Darlington (2000) } \\
\text { Scalia } \text { et al. (2011) } \\
\text { Benson } \text { et al. (2014) } \\
\text { Bohnhoff and Shackelford (2013) } \\
\text { Bohnhoff and Shackelford (2014) } \\
\text { Bohnhoff et al. (2014) } \\
\text { Scalia } \text { et al. (2014) } \\
\text { Scalia and Benson (2014) } \\
\text { Tian and Benson (2015) } \\
\text { Bohnhoff et al. (2016) } \\
\text { Tian } \text { et al. (2016a) }\end{array}$ \\
\hline $\begin{array}{l}\text { Contaminant-resistant } \\
\text { clay (CRC) GCLs }\end{array}$ & Proprietary & Unknown & $\begin{array}{l}\text { Ashmawy et al. (2002) } \\
\text { McRory and Ashmawy (2005) } \\
\text { Benson } \text { et al. (2010) } \\
\text { Shackelford et al. (2010) } \\
\text { Benson } \text { et al. (2014) } \\
\text { Arndt } \text { et al. (2015) } \\
\text { Athanassopoulos } \text { et al. (2015) } \\
\text { Tian \& Benson (2015) } \\
\text { Salihoglu et al. (2016) } \\
\text { Tian } \text { et al. (2016a) }\end{array}$ \\
\hline
\end{tabular}

also have been referred to as bentonite-polymer alloy (Trauger and Darlington 2000), bentonite-polymer nanocomposite (Scalia et al. 2011; Bohnhoff and Shackelford 2013), and bentonite-polymer composite (Scalia et al. 2014; Scalia and Benson 2017; Tian et al. 2017). BPC is oven dried and ground prior to use. Scalia et al. (2014) show that PAA does not intercalate in the montmorillonite interlayer within BPC based on a lack of measurable increase in interlayer $\left(d_{001}\right)$ spacing in dried BPC.

\subsubsection{Dense-prehydrated GCLs}

Dense-prehydrated GCLs, or DPH-GCLs, are GCLs that have been prehydrated to a water content of $\sim 43 \%$ using a dilute aqueous solution containing $\mathrm{Na}-\mathrm{CMC}$ and PAA, followed by subsequent densification via vacuum extrusion (Kolstad et al. 2004b). In addition to chemical modification, DPH-GCLs are physically modified by densification and prehydration (DPH-GCLs are not dried prior to use). Therefore, DPH-GCLs are unique among the EBs considered herein. The precise formulation of the chemical additives in the DPH-GCLs is proprietary.

\subsubsection{Contaminant-resistant clay}

Multiple GCL manufacturers sell products where the bentonite has been 'modified' with proprietary additives advertised to minimize the effect of aggressive chemicals on $k$. These materials are collectively classified herein as contaminant-resistant clays (CRCs, or when used in a GCL, CRC-GCLs), although the term 'resistant' is not universally accurate. CRCs typically are proprietary and, therefore, no information on specific additives or manufacture (Ashmawy et al. 2002; McRory and Ashmawy 2005; Benson et al. 2010a, 2010b, 2014; Shackelford et al. 2010; Arndt et al. 2015; Athanassopoulos et al. 2015; Salihoglu et al. 2016; Tian and Benson 2015; Tian et al. 2016a) is available. 


\section{HYDRAULIC BEHAVIOR}

\subsection{Ion concentration effects}

The concentration of inorganic ions in permeant liquids is typically quantified directly in terms of ionic strength, $I$, or indirectly by electrical conductivity, EC. Ionic strength is

$$
I=\frac{1}{2} \sum c_{i} z_{i}^{2}
$$

where $c_{i}=$ concentration (molarity) of ionic species $i$, and $z_{i}=$ charge of ionic species $i$. The ionic strength of real leachates generally is not known beforehand unless the concentrations of dissolved ionic species in solution and their activities are known (Stumm and Morgan 1996).

Electrical conductivity is a measure of the ability of a solution to conduct an electrical current and varies directly with the number and charge of ions in solution (Snoeyink and Jenkins 1980). Electrical conductivity is known to vary directly with ionic strength (Griffin and Jurinak 1973). The variation of ionic strength and electrical conductivity is shown in Figure 2. Data in Figure 2 are from the studies referenced in Table 1, for which both ionic strength (or data sufficient to calculate ionic strength) and EC were reported. In contrast to ionic strength, EC can be readily measured using an EC electrode and EC meter, and EC has been proposed as an indicator of equilibrium between effluent and influent

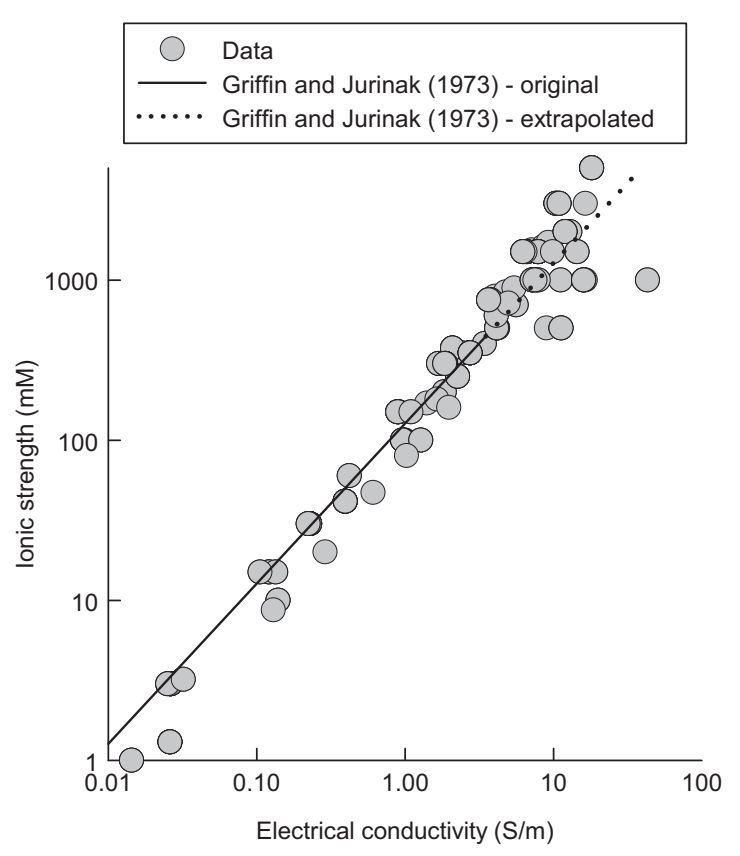

Figure 2. Comparison of ionic strength and electrical conductivity for tests conducted on enhanced bentonites and natural sodium bentonites for which both values are reported. The Griffin and Jurnak (1973) linear relationship between ionic strength and electrical conductivity is also shown up to the ionic strength limit at which the relationship was developed (ionic strength $=\mathbf{4 4 6} \mathrm{mM}$ ) and extrapolated to the full range of ionic strengths for which the relationship was used to translate electrical conductivities into ionic strengths in this study chemistry of permeant liquids for termination of hydraulic compatibility tests (Shackelford et al. 1999). Griffin and Jurnak (1973) report an approximate linear relationship between ionic strength and electrical conductivity $(I(\mathrm{mM})=0.0127 \times \mathrm{EC}(\mathrm{mS} / \mathrm{cm}))$ for natural waters. The linear relationship developed by Griffin and Jurnak (1973) was developed with natural waters, which had a maximum ionic strength of $446 \mathrm{mM}$. The data in Figure 2 suggest that the linear relationship extends to ionic strengths of at least $3000 \mathrm{mM}$.

Laboratory measured $k$ for EB-GCLs (MSB-GCLs, HC-GCLs, BPC, DPH-GCL and CRC-GCLs) and Na-B-GCLs reported in the literature (see Table 1) are shown as a function of the ionic strength of the permeant solution in Figure 3. The aforementioned linear relationship with EC reported by Griffin and Jurnak (1973) was used to calculate ionic strength for cases when only EC was provided. Tremendous variability in $k$ of unamended Na-B-GCLs is visible for ionic strength $\geq 20 \mathrm{mM}$, illustrating the need for GCL-permeant specific $k$ tests (termed hydraulic compatibility tests). Enhanced bentonite GCLs generally have lower $k$ for a given ionic strength. However, CRCs exhibit highly variable $k$ at higher ionic strength.

The $k$ for Na-B-GCLs is shown in Figure 3b. Data are separated into two categories based on whether the test was conducted at low $(<100 \mathrm{kPa})$ or high $(\geq 100 \mathrm{kPa})$ effective stress $\left(\sigma^{\prime}\right)$, and whether the specimen was prehydrated or not prior to permeation with the permeant liquid. More data are available for low ionic strength (generally baseline data with $I<0.2 \mathrm{mM}$ ) and elevated ionic strength $(I>20 \mathrm{mM}$ at which EB may be needed to meet containment specifications) than at mid-range ionic strength $(0.2 \mathrm{mM}<I<20 \mathrm{mM})$. Hydraulic conductivity generally increases with increasing ionic strength, although this trend is not universal. For example, permeation with a homo-ionic monovalent salt (electrolyte) solution can yield relatively low $k$ $\left(<5 \times 10^{-11} \mathrm{~m} / \mathrm{s}\right.$; Jo et al. 2001; Kolstad et al. 2004a; Katsumi et al. 2008). However, at elevated ionic strength $(>\sim 100 \mathrm{mM})$, the $k$ are generally $>5 \times 10^{-11} \mathrm{~m} / \mathrm{s}$. Prehydration does not appear to protect $k$ from adverse effects, nor does elevated $\sigma^{\prime}$ up to $500 \mathrm{kPa}$ with direct permeation (Kolstad et al. 2004b; Benson et al. 2014). Data for high $\sigma^{\prime}(\geq 100 \mathrm{kPa})$ with prehydration are limited, and plot on the lower range of observed $k$ behavior.

MSB- and HC-GCLs exhibit similar sensitivity to ionic strength as Na-B-GCLs, and tend to have lower $k$ for a permeant liquid of given ionic strength (Figures 3c and 3d). Limited data exist for these materials permeated after prehydration, or at high $\sigma^{\prime}(\geq 100 \mathrm{kPa})$. The data in Figures $3 \mathrm{e}$ and $3 \mathrm{f}$ illustrate that BPC-GCLs and DPH-GCLs do not exhibit the typical sensitivity of $k$ to ionic strength. BPC exhibits a reduction in $k$ at elevated ionic strength (Figure 3e), whereas DPH-GCLs generally appear insensitive to ionic strength (Figure 3f). Similar to Na-B-GCLs, CRC-GCLs exhibit high variability in $k$ for similar ionic strength (Figure $3 \mathrm{~g}$ ), although a greater portion (approximately half) of CRC-GCLs yield low $k$ 


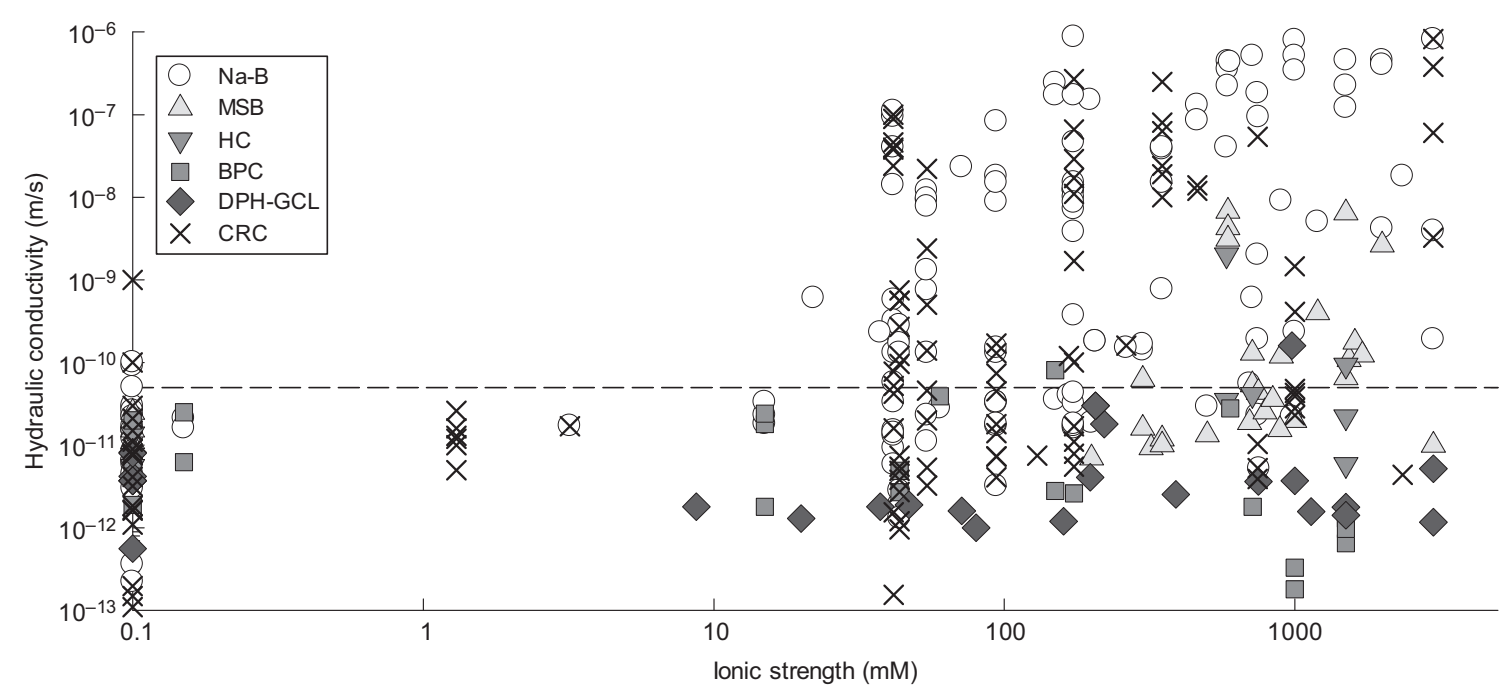

(a)
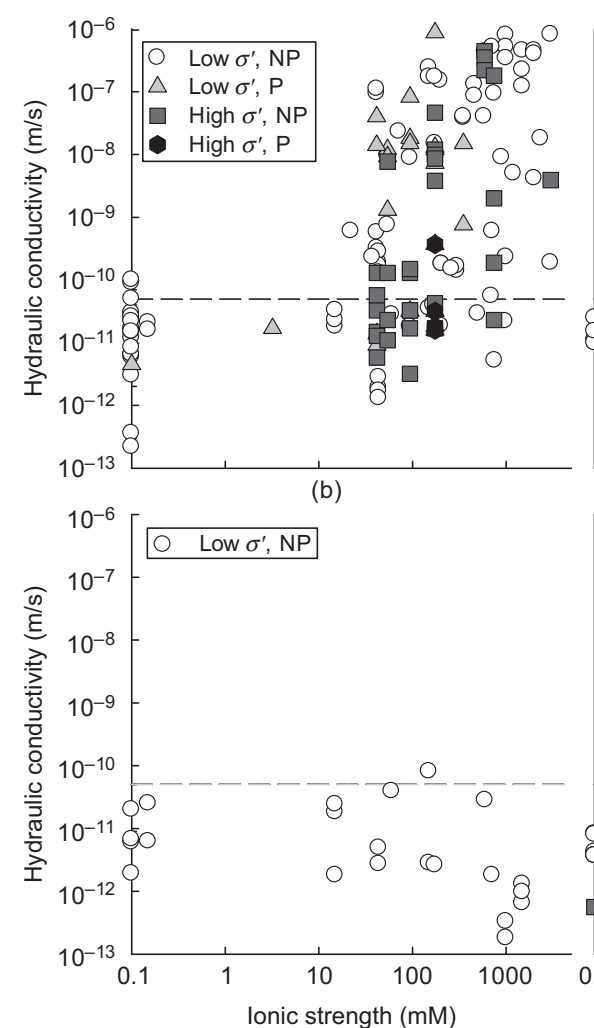

(e)

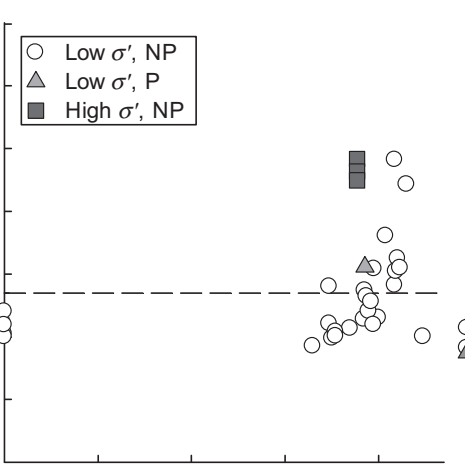

(c)

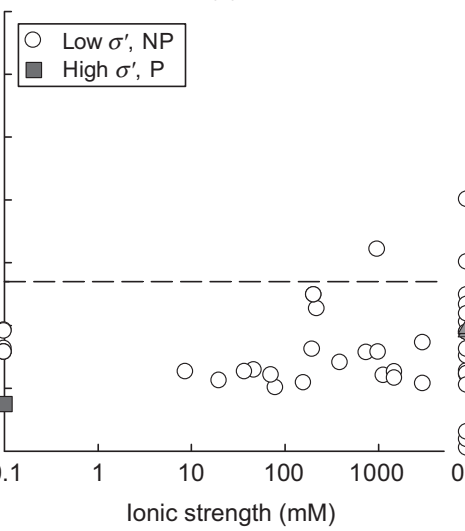

(f)

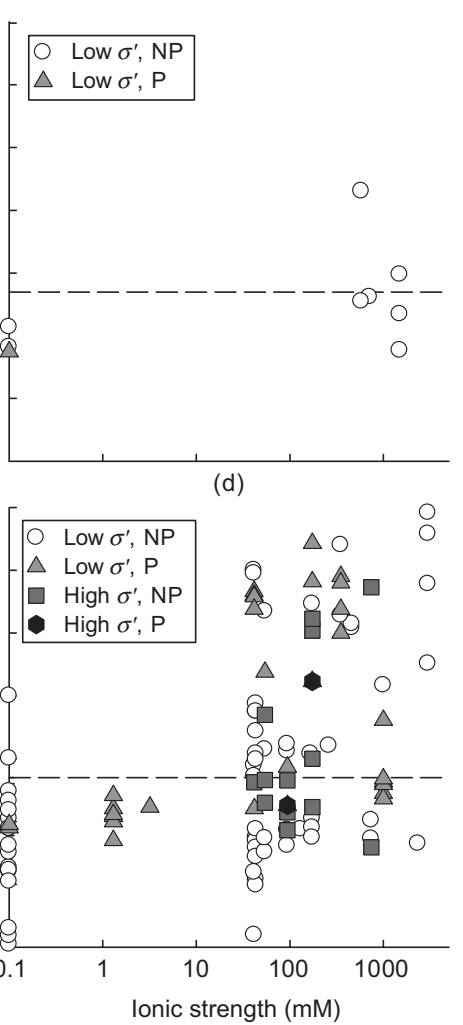

(g)

Figure 3. Hydraulic conductivity of enhanced bentonites and natural sodium bentonite, Na-B, versus permeant ionic strength for all stress and prehydration conditions (a), and for Na-B (b), multiswellable bentonite, MSB (c), HYPER-clay, HC (d), bentonite-polyacrylic-acid composite, BPC (e), dense prehydrated geosynthetic clay liner, DPH-GCL (f), and proprietary contaminant resistant clays, CRCs (g), for low $(<100 \mathrm{kPa})$ and high $(\geq 100 \mathrm{kPa})$ effective stress $\left(\sigma^{\prime}\right)$ conditions and with $(\mathrm{P})$ and without $(\mathrm{NP})$ prehydration with a more dilute solution

$\left(<5 \times 10^{-11} \mathrm{~m} / \mathrm{s}\right)$ to solutions with high concentrations $(I>100 \mathrm{mM})$. Due to the variability in $k$ illustrated in Figure $3 \mathrm{~g}$ and the proprietary nature of these materials, hydraulic compatibility tests on CRCs are particularly important to ensure low $k$.

The data in Figure 3 do not differentiate between permeant solutions with different cation compositions. Kolstad et al. (2004a) showed that, for a given ionic strength, a lower RMD in the permeant solution equated to a somewhat higher $k$. However, ionic strength dominated $k$ behavior at high ionic strengths, presumably due to limited or negligible osmotic swelling. Because EBs are intended to function in the range of ionic strengths where osmotic swelling of $\mathrm{Na}-\mathrm{B}$ is negligible, the effects of variations in RMD are not included in Figure 3. Thus, additional study is needed to assess the full effects of RMD on EBs. Moreover, Tian et al. (2017) showed that the ratio of monovalent-to-divalent anions affects $k$ but not the swell index of a commercially available EB, even though anion species generally do not affect $k$ or swell 


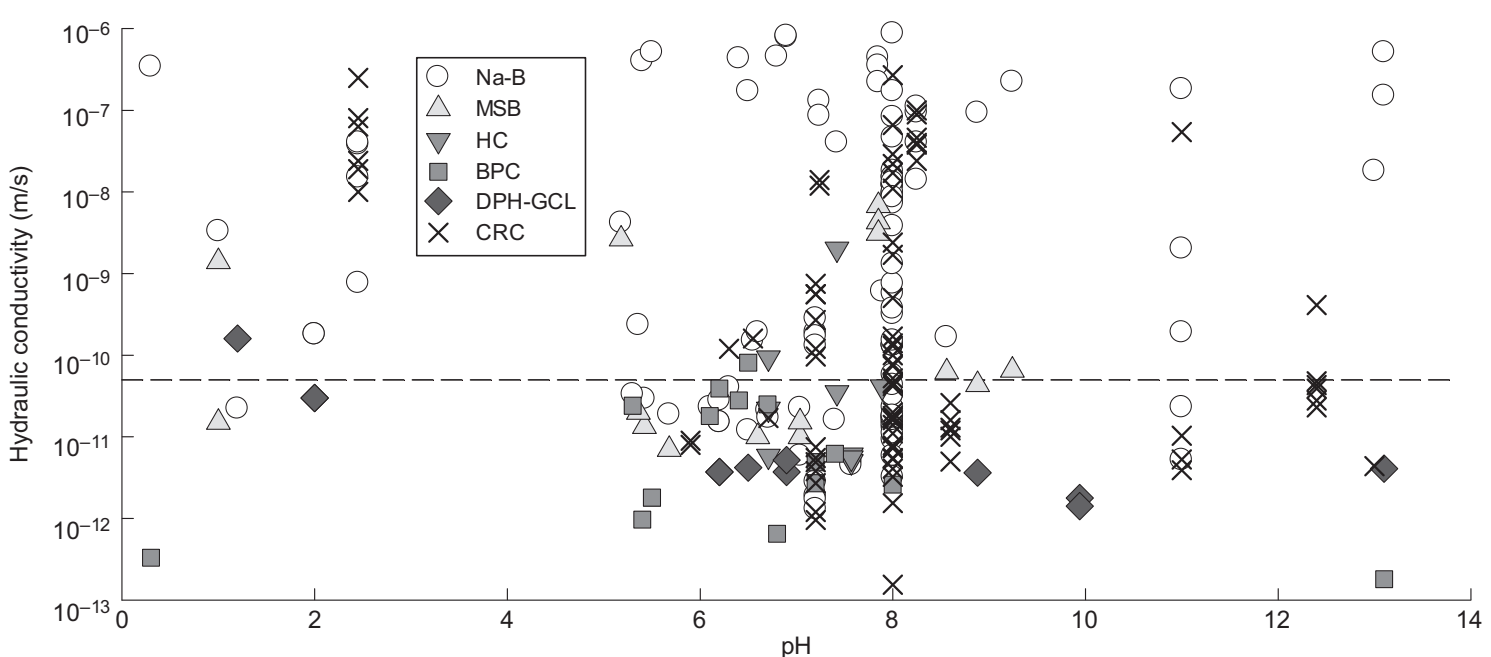

(a)
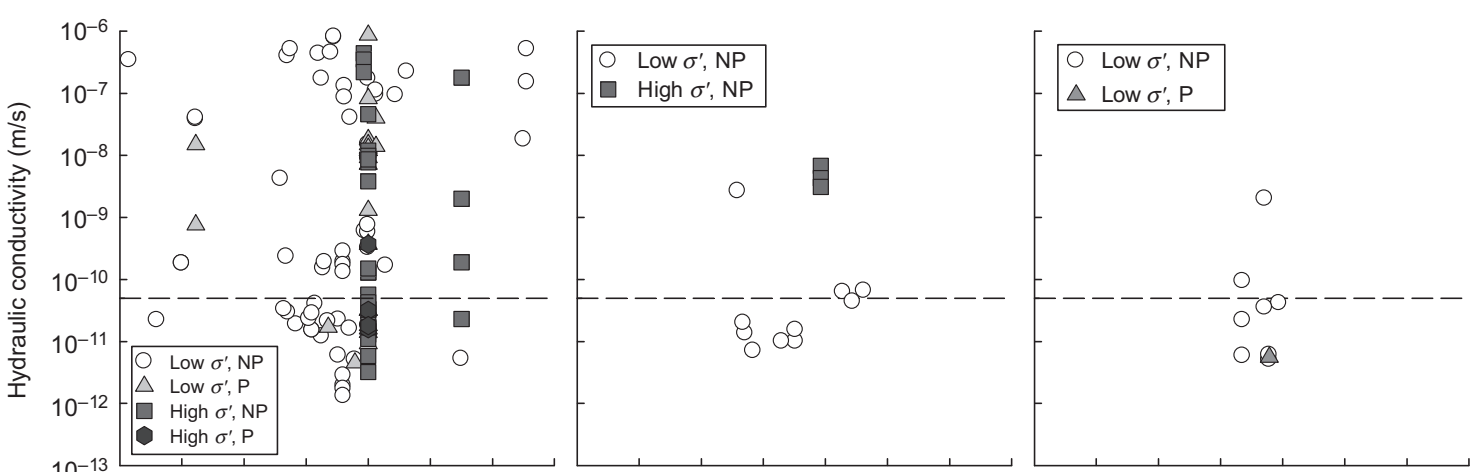

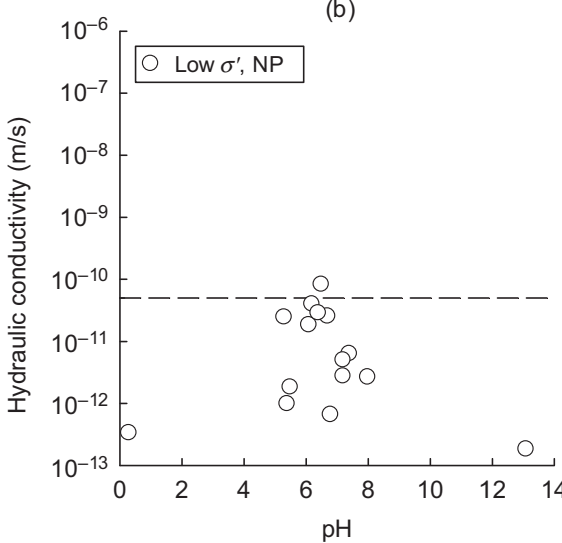

(e)

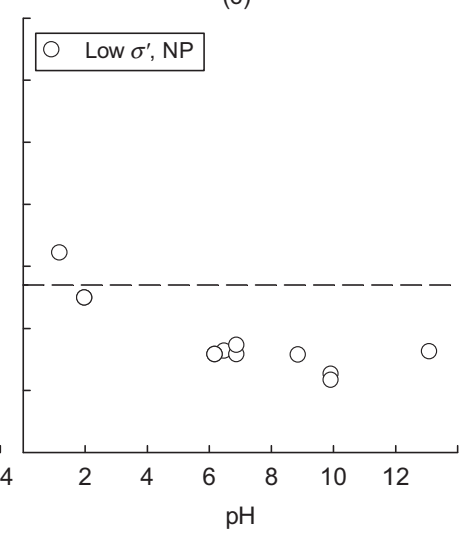

(f)

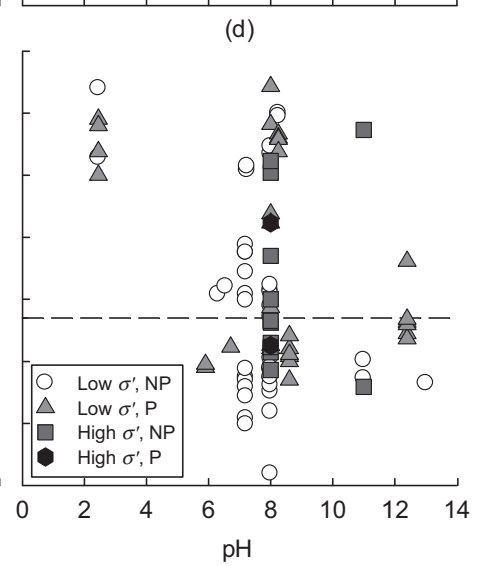

(g)

Figure 4. Hydraulic conductivity of enhanced bentonites and natural sodium bentonite, Na-B, versus pH of permeant solution for all stress and prehydration conditions (a), and for Na-B (b), multiswellable bentonite, MSB (c), HYPER-clay, HC (d), bentonite-polyacrylic-acid composite, BPC (e), dense prehydrated geosynthetic clay liner, DPH-GCL (f), and proprietary contaminant resistant clays, CRCs (g), for low $(<100 \mathrm{kPa})$ and high $(\geq 100 \mathrm{kPa})$ effective stress $\left(\sigma^{\prime}\right)$ conditions and with $(\mathrm{P})$ and without $(\mathrm{NP})$ prehydration with a more dilute solution

index of Na-B. Anion effects are not explored in Figure 3, but warrant additional study.

\section{2. $\mathrm{pH}$ effects}

The effect of permeant solution $\mathrm{pH}$ on $k$ is shown in Figure 4. As previously discussed, the $k$ to permeant solutions with relatively neutral $\mathrm{pH}(4<\mathrm{pH}<10)$ are affected primarily by the ionic strength of the solution (Figure 4a). Data for EB-GCLs at extreme $\mathrm{pH}$ corresponding to hyper-acidic $(\mathrm{pH}<2)$, or hyper-alkaline
$(\mathrm{pH}>12)$ solutions are limited. Data for Na-B-GCLs shown in Figure $4 \mathrm{~b}$ illustrate high variability in $k$ at hyper-acidic and hyper-alkaline $\mathrm{pH}$. The lack of data at hyper-acidic and hyper-alkaline $\mathrm{pH}$ for MSB-GCLs and HC-GCLs is demonstrated in Figures $4 \mathrm{c}$ and $4 \mathrm{~d}$. Low $k$ at both $\mathrm{pH}$ extremes is exhibited by BPC-GCLs (Figure 4e). However, the data pertain to simple solutions $\left(\mathrm{HNO}_{3}\right.$ or $\left.\mathrm{NaOH}\right)$ and may not represent behavior of real-world leachates containing other ions, acids, or bases. DPH-GCLs also exhibit low $k$ at extreme $\mathrm{pH}$ (Figure 4f), 


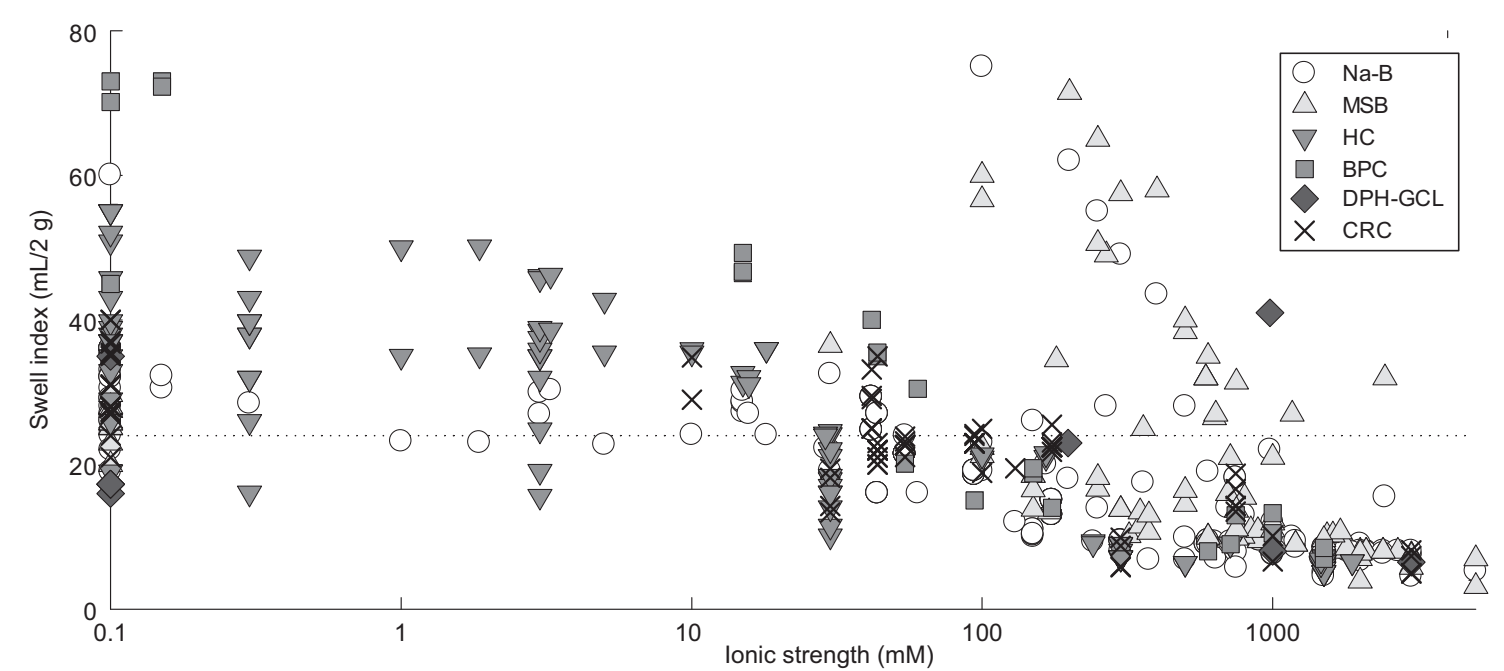

(a)

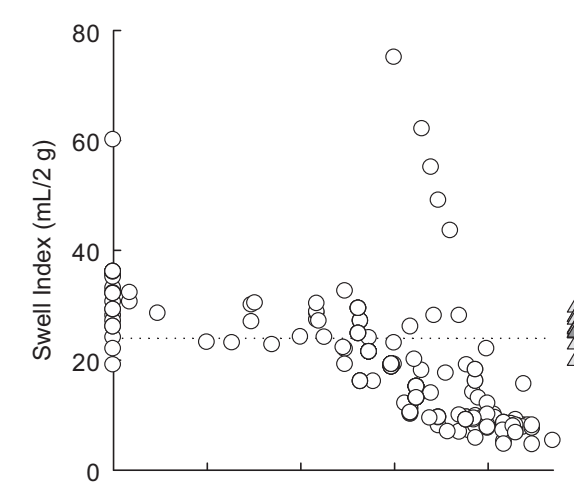

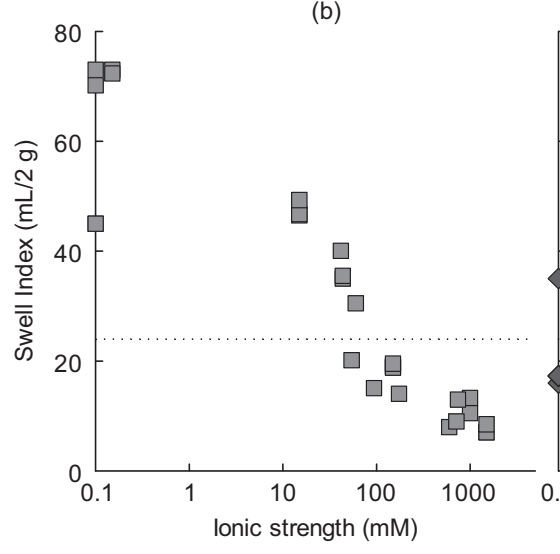

(e)

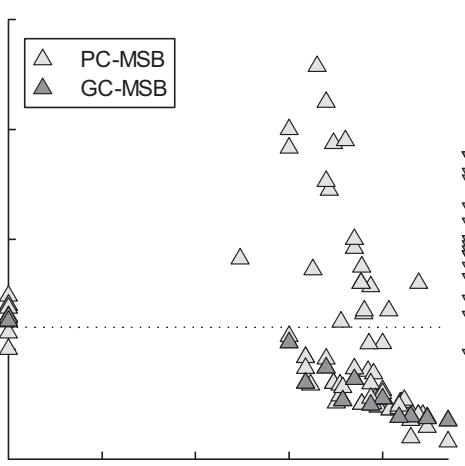

(c)

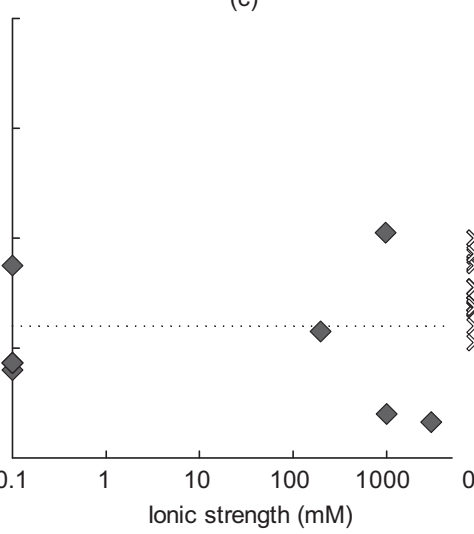

(f)

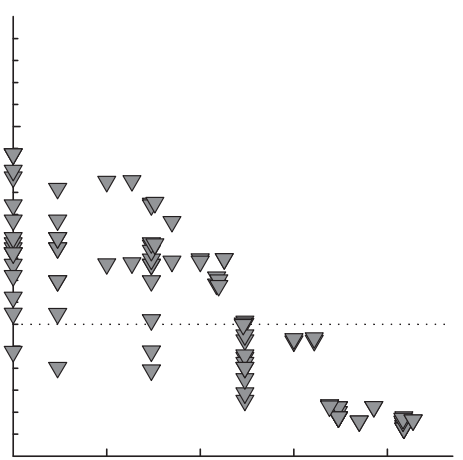

(d)

Figure 5. Swell index of enhanced bentonites and natural sodium bentonite, Na-B versus hydrating solution ionic strength (a), and for Na-B, (b), multiswellable bentonite, MSB, (c) HYPER-clay, HC, (d) bentonite-polyacrylic-acid composite, BPC, (e) dense prehydrated geosynthetic clay liner, DPH-GCL, and (f) proprietary contaminant resistant clays, CRCs. Data for MSB are subdivided by additive

but similar to the BPC-GCLs, data are limited. The data in Figure 4g illustrate that CRC-GCLs appear to often yield low $k\left(<5 \times 10^{-11} \mathrm{~m} / \mathrm{s}\right)$ to hyper-alkaline solutions, both with and without prehydration, but low $k$ for CRC-GCLs with hyper-acidic solutions has not been demonstrated.

\section{INDICATOR PARAMETERS}

Swell index (SI), liquid limit (FL), and fluid loss (FL) commonly are used as indicators of compatibility between the Na-B component of GCLs and leachates (e.g. Lee and
Shackelford 2005b; Lee et al. 2005; Liu et al. 2013). Their potential use for evaluating compatibility of EB-GCLs has not been addressed systematically. Solution retention capacity (Lee and Shackelford 2005b; Fehervari et al. 2016) and swelling pressure (Di Emidio 2010) have also been proposed, but neither has been adopted in practice and standardized methods do not exist to measure these parameters.

\subsection{Swell index}

Swell index is shown versus ionic strength of the hydrating solution for Na-Bs and EBs in Figure 5. The SI were 


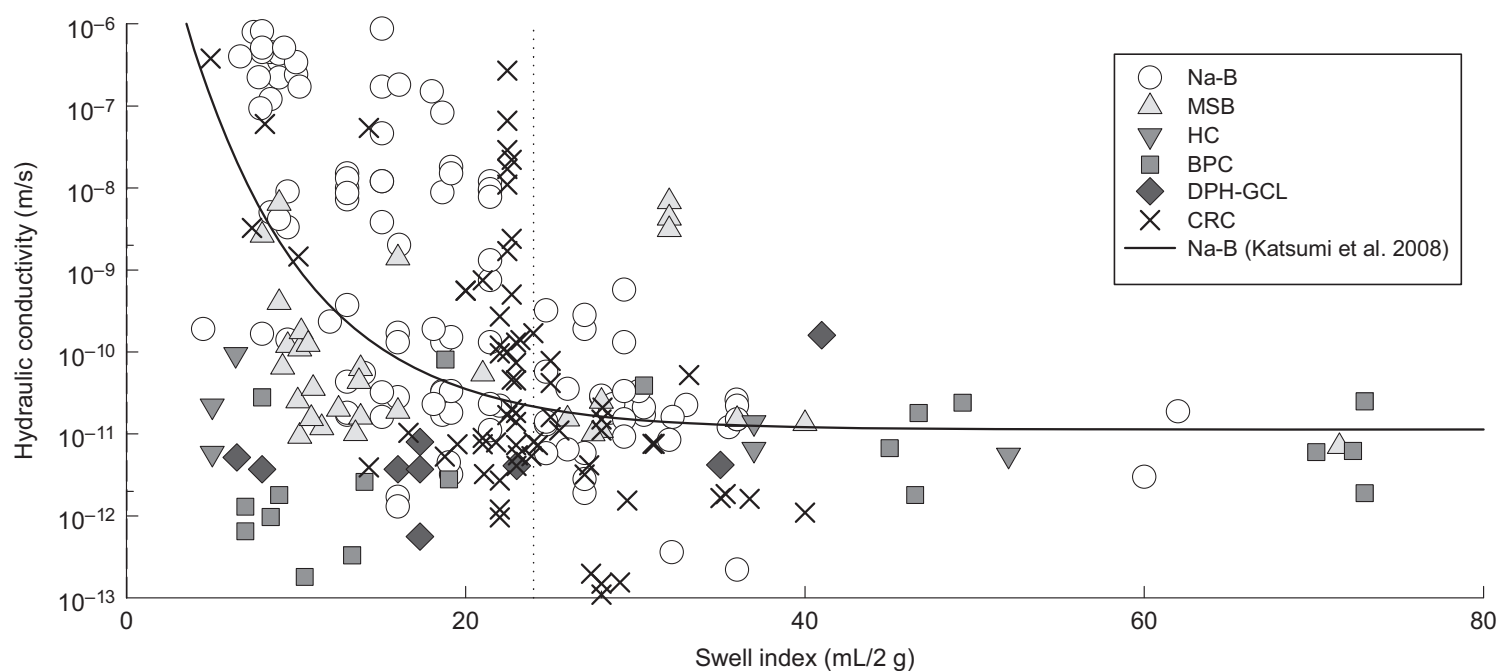

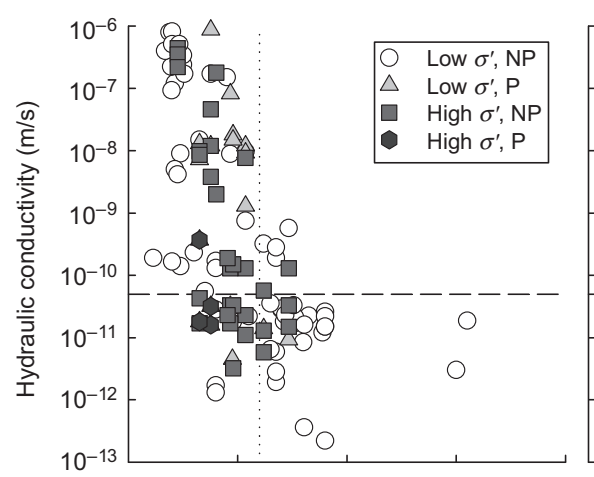

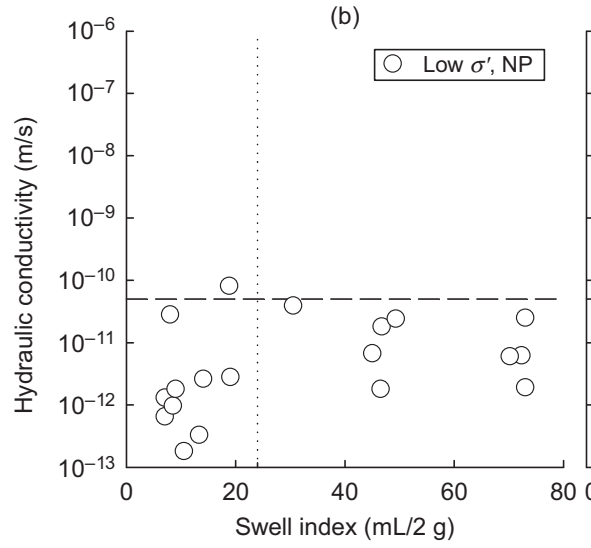

(e)

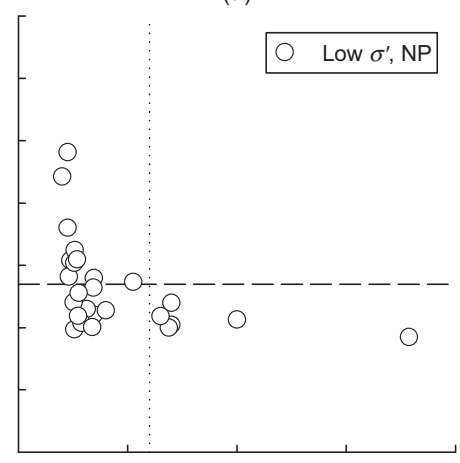

(c)

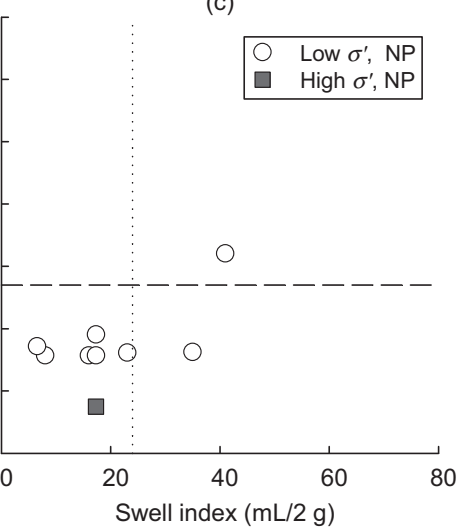

(f)

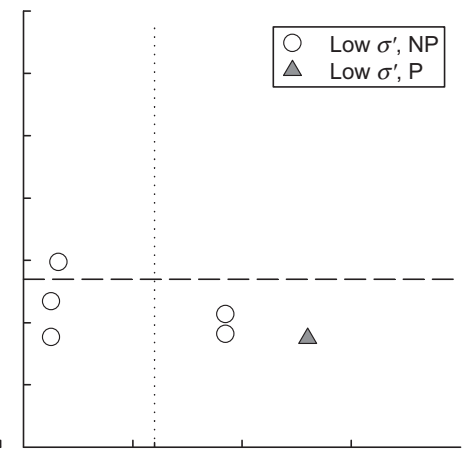

(d)

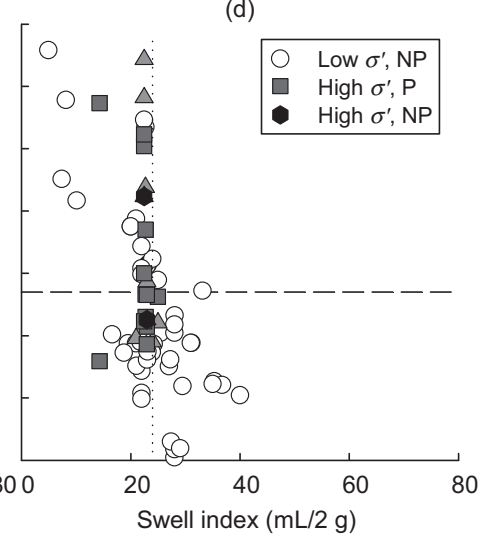

(g)

Figure 6. Hydraulic conductivity of hydraulically enhanced bentonites and natural sodium bentonite, Na-B, versus swell index in the same solution for all stress and prehydration conditions (a), and for Na-B (b), multiswellable bentonite, MSB (c), HYPER-clay, HC (d), bentonite-polyacrylic-acid composite, BPC (e), dense prehydrated geosynthetic clay liner, DPH-GCL (f), and proprietary contaminant resistant clays, CRCs (g), for low $(<100 \mathrm{kPa})$ and high $(\geq 100 \mathrm{kPa})$ effective stress $\left(\sigma^{\prime}\right)$ conditions and with (P) and without (NP) prehydration with a more dilute solution

measured using the procedure in ASTM D5890, except permeant solutions were used instead of DI water. The data indicate that SI diminishes with increasing ionic strength for all EBs, similar to Na-B. BPC and HC exhibit higher SI than Na-B at low ionic strength, but the SI transitions to a range typical of $\mathrm{Na}-\mathrm{B}$ at ionic strength higher than about $50 \mathrm{mM}$. High SI $(>20 \mathrm{ml} / 2 \mathrm{~g})$ at high ionic strength $(\geq 100 \mathrm{mM})$ are only exhibited for homo-ionic monovalent solutions (e.g. $\mathrm{NaCl}$ ) as reported by Onikata et al. (1996), Lin et al. (2000), and Katsumi et al. (2008). At higher ionic strength $\gtrsim 200 \mathrm{mM}$ with multivalent solutions, the $S I$ of EBs and Na-Bs converge to the same range.

Hydraulic conductivity is shown versus SI measured with the permeant solution for Na-B-GCLs and EB-GCLs in Figure 6. For Na-B-GCLs (Figure 6b), $k>10^{-10} \mathrm{~m} / \mathrm{s}$ generally correspond to $\mathrm{SI}<20 \mathrm{ml} / 2 \mathrm{~g}$, whereas lower $k\left(<5 \times 10^{-11} \mathrm{~m} / \mathrm{s}\right)$ generally correspond to $\mathrm{SI}>20 \mathrm{ml} / 2 \mathrm{~g}$ (Figure $6 \mathrm{~b}$ ). Factors such as higher $\sigma^{\prime}$ and prehydration can yield inconsistencies in the relationship between $k$ and SI for Na-B-GCLs, as indicated by the scatter in Figure 6b. Nonetheless, the data in 
Figure $6 \mathrm{~b}$ illustrate that $\mathrm{SI}$ is a reasonable indicator of $k$ on Na-B-GCLs, particularly at low $\sigma^{\prime}$ and without prehydration, as suggested by Jo et al. (2001), Kolstad et al. (2004a), Lee et al. (2005), Katsumi et al. (2008), Chen et al. (2018).

Correspondence between $k$ and SI at low $\sigma^{\prime}$ and without prehydration is evident for MSB-GCLs (Figure 6c) and CRC-GCLs (Figure 6g), with $k$ decreasing significantly with increasing SI from 5 to $24 \mathrm{ml} / 2 \mathrm{~g}$, and then being nearly unaffected by SI at $>24 \mathrm{ml} / 2 \mathrm{~g}$. No data exist for prehydrated MSB or MSB permeated at high $\sigma^{\prime}$. CRC-GCLs exhibit an approximately linear relationship between $k$ and $S I$ for non-prehydrated specimens permeated at low $\sigma^{\prime}$ (Figure 6g). However, limited data for prehydrated CRC-GCLs, or CRC-GCLs permeated at high $\sigma^{\prime}$, suggest $k$ of these materials are independent of SI, with $k$ ranging over four orders of magnitude at similar SI.

The $k$ of BPC (Figure 6e), and DPH-GCLs (Figure 6f) appears to be unrelated to SI, with low $k$ independent of SI. Limited or no data exist for prehydration or high $\sigma^{\prime}$ for HC-GCLs, BPC-GCLs, or DPH-GCLs. Mechanisms governing the behavior of these EB-GCLs are discussed subsequently. Except for MSB-GCLs (and possibly HC, for which sparse data are available), SI appears to be ineffective as an indicator of $k$ for EB-GCLs.

\subsection{Liquid limit}

Liquid limit, LL, measured using ASTM D4318 except with permeant liquid used as the hydrating solution is shown versus ionic strength for Na-B and EB in Figure 7a. Similar to Na-B, LL of MSB and DPH bentonite decreases with increasing ionic strength. Insufficient data are available for $\mathrm{HC}, \mathrm{BPC}$, and CRCs to determine if $\mathrm{LL}$ varies in a similar manner with ionic strength.

Hydraulic conductivity is shown versus LL in Figure $7 \mathrm{~b}$. The data that are available are limited to $k$ tests conducted without prehydration at low $\sigma^{\prime}(<35 \mathrm{kPa})$. The $k$ of Na-B- and MSB-GCLs is inversely related to LL. Conversely, the $k$ of DPH-GCLs is directly related to LL, suggesting that the mechanism controlling the $k$ of DPH-GCLs is different from those controlling Na-B and DPH-GCLs. Only one data point, from tests with DI water, is available for HC- and BPC-GCLs; these data are insufficient to confirm if HC- and BPC-GCLs follow the same trend as Na-B- and MSB-GCLs. Overall, the limited data in Figure $7 \mathrm{~b}$ illustrate the potential use of $L L$ as an indicator of $k$, but only for Na-B- and MSB-GCLs. Additional data are needed to understand the effectiveness of $L L$ as an indicator parameter for $\mathrm{HC}, \mathrm{BPC}$, or CRCs.

\subsection{Fluid loss}

Fluid loss determined by ASTM D5891 using leachate as the hydration solution is shown versus ionic strength for Na-B and EB in Figure 8a. Na-B and MSB exhibit increasing fluid loss with increasing ionic strength, although MSB exhibits a general pattern of similar fluid loss at an elevated range of ionic strengths relative to Na-B. Dissimilarly, BPC exhibits a similar, low, FL up to an ionic strength of approximately $150 \mathrm{mM}$, but then

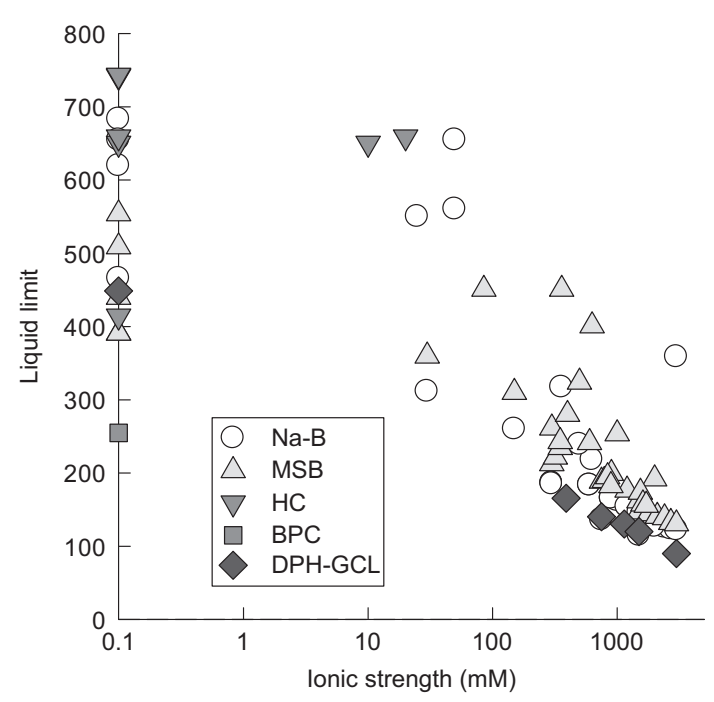

(a)

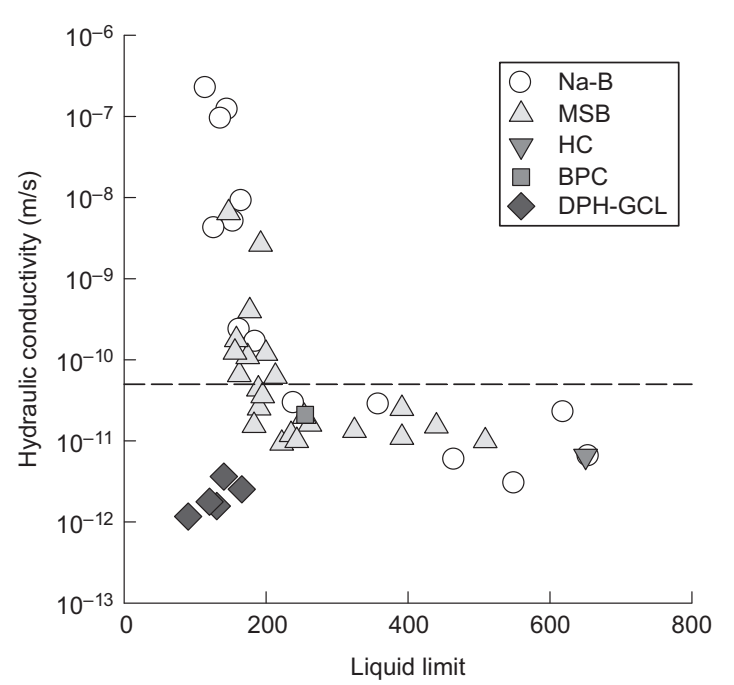

(b)

Figure 7. Hydraulic conductivity of enhanced bentonites (multiswellable bentonite, MSB, HYPER-clay, HC, and dense prehydrated geosynthetic clay liners, DPH-GCLs) and natural sodium bentonite, Na-B, versus liquid limit of material hydrated with same solution

exhibits both low and high (to a range similar to Na-B) $\mathrm{FL}$ at ionic strengths $\geq 600 \mathrm{mM}$. There is no clear relationship between FL and ionic strength of CRCs.

Limited fluid loss data with paired hydraulic conductivities have been published for EBs. In Figure 8b, $k$ is presented versus fluid loss. All data are for $k$ tests conducted without prehydration at low $\sigma^{\prime}(<35 \mathrm{kPa})$. Similar to SI, fluid loss is used as an indicator for bentonite quality when testing is conducted with DI water (e.g. GRI-GCL3 requires a fluid loss $<18 \mathrm{ml}$ ), and as an indicator of compatibility in $k$ when testing is conducted with a chemical solution. For Na-B-GCLs, a fluid loss $>60 \mathrm{ml}$ correlates with a high $k$ (Figure $8 \mathrm{~b}$ ). The $k$ of BPC-GCLs appears to be decoupled from fluid loss, similar to the trend between $\mathrm{k}$ and SI for BPC. Limited or no data are available for HC-, MSB-, and CRC-GCLs. As in the cases with SI and LL, fluid loss may not be an effective indicator of compatibility in $k$ of EB-GCLs for 


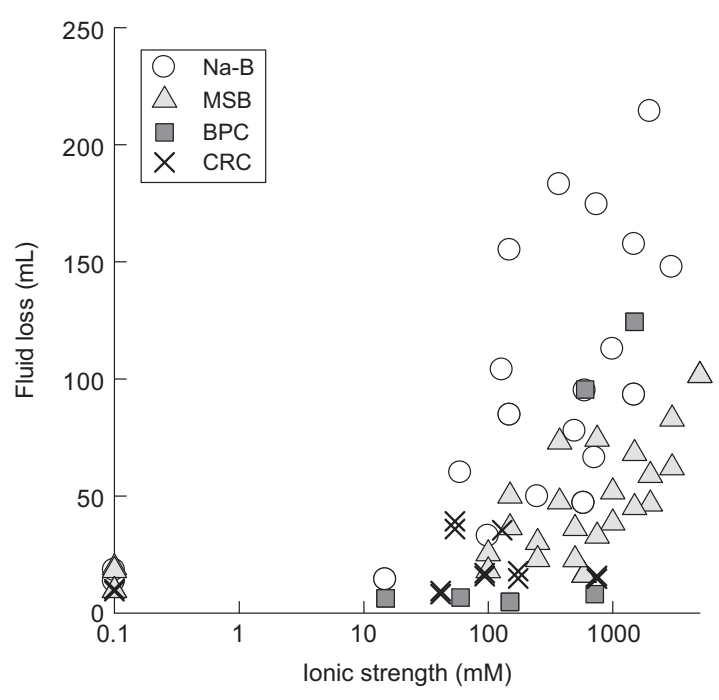

(a)

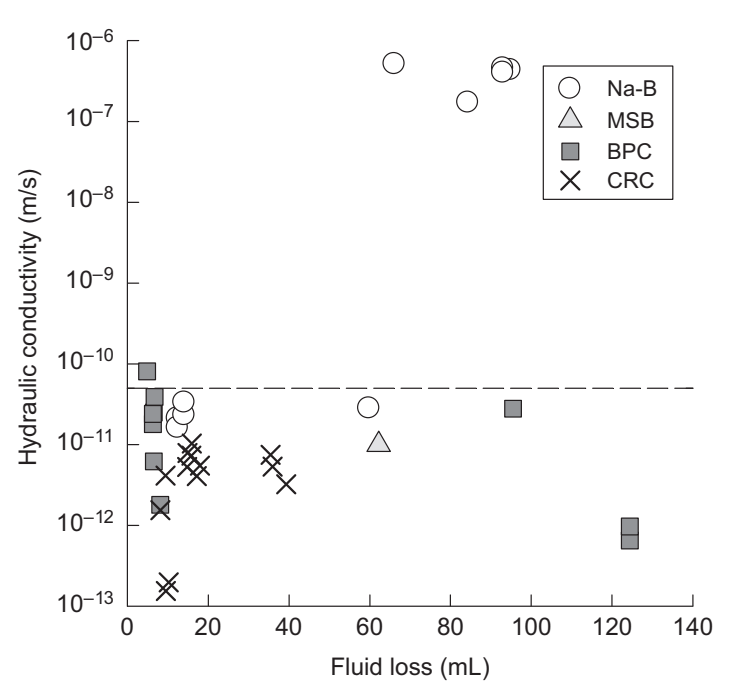

(b)

Figure 8. Hydraulic conductivity of enhanced bentonites (multiswellable bentonite, MSB bentonite-polyacrylic-acid composite, BPC, and proprietary contaminant resistant clays, CRCs) and natural sodium bentonite, Na-B, versus fluid loss of material with same solution

some EB-GCLs, although these indicator parameters may still be effective for MSB-GCLs. No fluid loss data are available for $\mathrm{HC}$.

\section{DIFFUSION}

Limited diffusion data are available for GCLs with both traditional $\mathrm{Na}-\mathrm{B}$ and $\mathrm{EB}$ due to the challenging and time-consuming nature of diffusion tests. However, at low $k\left(<10^{-10} \mathrm{~m} / \mathrm{s}\right)$, diffusion has been shown to be a significant if not dominant chemical transport mechanism (Foose et al. 2002; Shackelford 2014). Therefore, understanding of diffusive transport through EB-GCLs is essential to evaluating the performance of EBs.

Effective diffusion coefficients as defined by Shackelford and Daniel (1991), $D^{*}$, of $\mathrm{Cl}^{-}$for EBs are shown in Figure $9 \mathrm{a}$ as a function of ionic strength of simple salt solutions $\left(\mathrm{KCl}\right.$ or $\left.\mathrm{CaCl}_{2}\right)$. The $D^{*}$ for the EB-GCLs

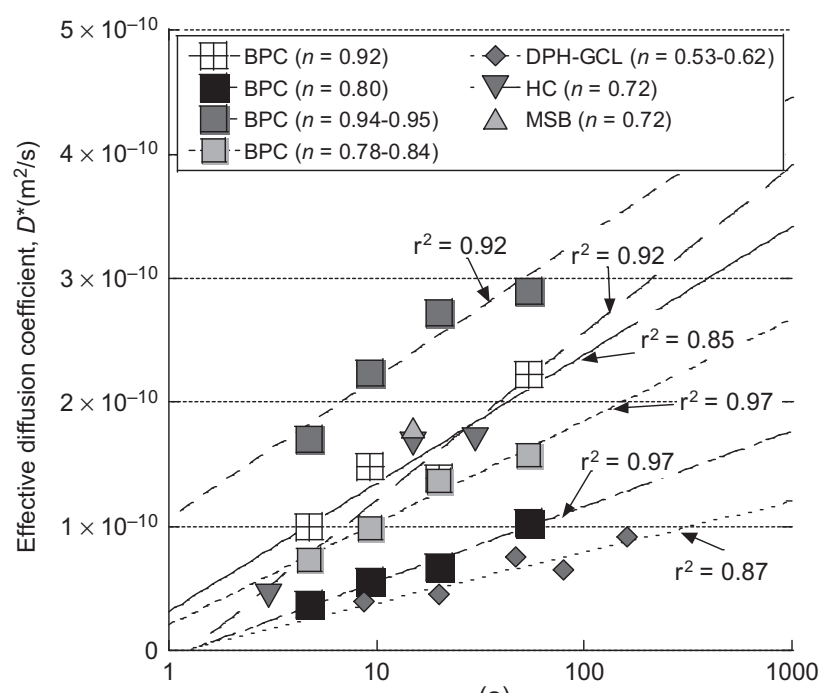

(a)

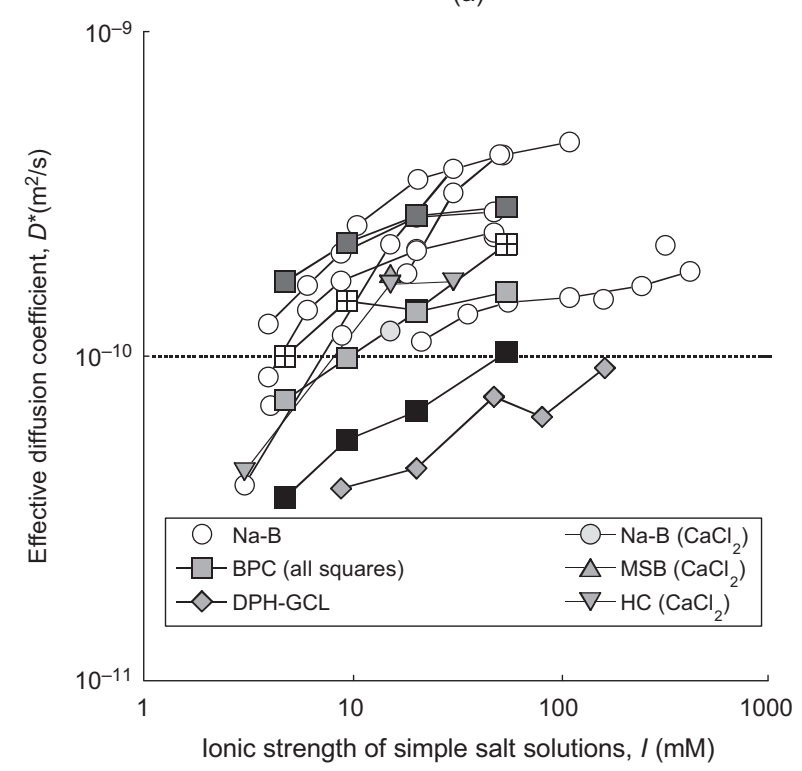

(b)

Figure 9. Comparison of effective diffusion coefficients for diffusion of chloride through enhanced bentonites (multiswellable bentonite, MSB, HYPER-clay, HC, bentonite-polyacrylic-acid composite, BPC, dense prehydrated geosynthetic clay liner, DPH-GCL) and Na-B as a function of ionic strength of simple salt solutions (KCl for BPC, DPH-GCL, and $\mathrm{Na}-\mathrm{B} ; \mathbf{C a C l}_{\mathbf{2}}$ for HC, MSB and Na-B): (a) semi-log linear regression diffusion coefficients; (b) effect of type of material

including BPC, DPH-GCL, HC and MSB vary from $3.7 \times 10^{-11} \mathrm{~m}^{2} / \mathrm{s}$ to $2.9 \times 10^{-10} \mathrm{~m}^{2} / \mathrm{s}$ for $3.9 \mathrm{mM} \leq$ ionic strength $\leq 160 \mathrm{mM}$. In general, $D^{*}$ increases as ionic strength increases in an approximately semi-log linear relationship. Semi-log linear regressions and the corresponding coefficients of determination, $r^{2}$, are presented together with the data in Figure 9a. In addition, $D^{*}$ is dependent on the type of EB and the porosity, $n$, of the material. The $D^{*}$ for DPH-GCL are the lowest among all the EB-GCL and range from $3.9 \times 10^{-11}$ at ionic strength $=8.7 \mathrm{mM}$ to $9.2 \times 10^{-11} \mathrm{~m}^{2} / \mathrm{s}$ at ionic strength $=160 \mathrm{mM}$, which is consistent with lowest $n$ for DPH-GCL among all the EB-GCL summarized in Figure 9a. The $D^{*}$ for the BPC-GCL increase with 
increasing $n$. For example, the highest $D^{*}$ of $2.2 \times 10^{-10}$ and $2.9 \times 10^{-10} \mathrm{~m}^{2} / \mathrm{s}$ for ionic strength $=54 \mathrm{mM}$ occur for the BPC-GCL with the highest $n$ of 0.92 and 0.94-0.95, respectively. Although the $n$ of the HC-GCL is relatively low (0.72), the $D^{*}$ at ionic strength $>10 \mathrm{mM}$ is similar to that for the BPC at higher $n$ (e.g. 0.92). This increase in $D^{*}$ may be attributed, in part, to the salt solution used in these tests $\left(\mathrm{CaCl}_{2}\right.$ for the $\mathrm{HC}-\mathrm{GCL}$ vs. $\mathrm{KCl}$ for the BPC-GCL) and the interactions of the divalent cation $\mathrm{Ca}^{2+}$ with $\mathrm{HC}$.

The $D^{*}$ for EB-GCL are compared with the $D^{*}$ for traditional Na-B-GCL in Figure 9b. In general, $D^{*}$ for the EB-GCL are similar to or less than that for the Na-B-GCL. The $D^{*}$ for the BPC- $(n>0.80)$, MSB-, and the HC-GCL are generally within the range of $D^{*}$ reported for Na-B-GCL $\left(\approx 7 \times 10^{-11}\right.$ to $\left.4 \times 10^{-10} \mathrm{~m}^{2} / \mathrm{s}\right)$. The $D^{*}$ for the BPC-GCL $(n=0.80)$ and the DPH-GCL are lower than the $D^{*}$ for Na-B-GCL at similar ionic strength. For example, at ionic strength $=20 \mathrm{mM}$, the $D^{*}$ for BPC-GCL $(n=0.80)$ and DPH-GCL are $6.8 \times 10^{-11}$ and $4.5 \times 10^{-11} \mathrm{~m}^{2} / \mathrm{s}$, respectively, whereas for Na-B-GCL, the $D^{*}$ at ionic strength $\approx 20 \mathrm{mM}$ is $>1 \times 10^{-10} \mathrm{~m}^{2} / \mathrm{s}$. However, the trend of increasing $D^{*}$ with increasing ionic strength is consistent for both Na-B- and EB-GCL. This trend is consistent with diffuse double-layer (DDL) theory and the swell index results (e.g. decreasing SI with increasing ionic strength for Na-B- and EB-GCL). In addition, as previously shown, $k$ for the EB-GCL typically are less than $k$ for Na-B-GCL.

However, as shown in Figure 10 for tests involving $5 \mathrm{mM} \mathrm{CaCl}_{2}$, the decrease in $D^{*}$ is not uniquely related to the decrease in $k$ for the different types of EB-GCL, indicating that lower $k$ relative to Na-B-GCL does not necessarily correspond with lower $D^{*}$ for EB-GCL. For example, although a HC-GCL exhibited the lowest $k$ $\left(5.3 \times 10^{-12} \mathrm{~m} / \mathrm{s}\right)$ for $5 \mathrm{mM} \mathrm{CaCl}_{2}$, the BPC-GCL had a lower diffusion coefficient $\left(D^{*}\right.$ for $\left.\mathrm{Cl}^{-}=1.7 \times 10^{-10} \mathrm{~m}^{2} / \mathrm{s}\right)$. The results shown in Figure 10 indicate the importance of evaluating and comparing the hydraulic and diffusive properties of EB-GCL. Additional $D^{*}$ data for real and

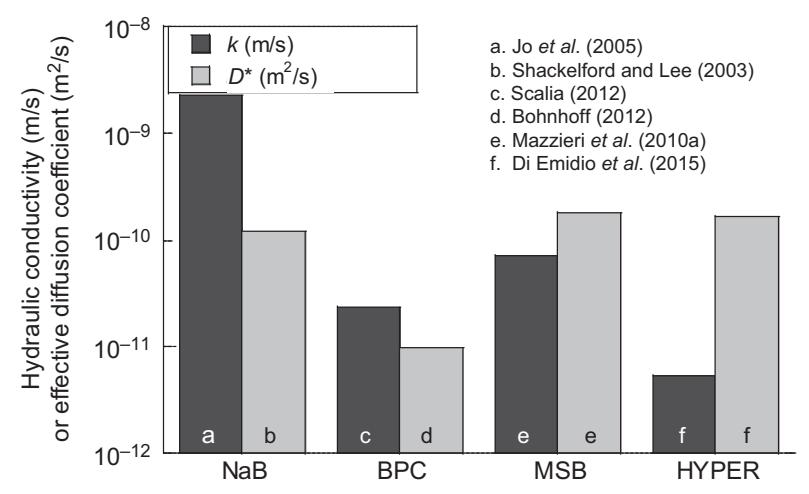

Figure 10. Hydraulic conductivity $(k)$ and effective diffusion coefficients $\left(D^{*}\right)$ for Na-bentonite (Na-B) and enhanced bentonites (multiswellable bentonite, MSB, HYPER-clay, HC, bentonite-polyacrylic-acid composite, BPC, dense prehydrated geosynthetic clay liner, DPH-GCL) for test solutions of $5 \mathrm{mM}$ $\mathrm{CaCl}_{2}$ synthetic leachates are recommended to evaluate the overall improved properties of EB-GCLs for containment systems.

\section{MEMBRANE BEHAVIOR}

GCLs comprising sodium bentonite have been shown to exhibit semipermeable membrane behavior - that is, the ability to selectively restrict the migration of solutes through the pores (e.g. Malusis and Shackelford 2002b; Kang and Shackelford 2011; Meier et al. 2014; Shackelford and Scalia 2016). Membrane behavior restricts solute migration and chemico-osmosis, by reducing diffusive transport of contaminants and promoting hyperfiltration and chemico-osmotic counter advection (Malusis et al. 2003).

The membrane efficiency coefficient, $\omega$, is used to quantify the magnitude of solute restriction, and generally ranges from zero to unity $(0 \leq \omega \leq 1)$, where $\omega=0$ indicates no solute restriction (no membrane behavior) and $\omega=1$ indicates complete solute restriction corresponding to perfect or ideal membrane behavior. The ability of clays to restrict solute migration is a function of the pore sizes. Clays that exhibit solute restriction $(\omega>0)$ are referred to as semipermeable membranes (Shackelford 2013).

A detailed description of the measurement of $\omega$ is provided in Malusis et al. (2001). In brief, $\omega$ is measured by circulating a chemical solution containing one or more solutes at specified concentrations across the top boundary of the specimen, while simultaneously circulating DI water across the bottom of the specimen. Circulation rates are sufficiently fast that the boundary concentrations can be considered constant. In the case of a closed system (e.g. Malusis et al. 2001), the circulation systems are closed loops, such that there can be no volume change in the system. Thus, in the case where the specimen behaves as a semipermeable membrane, there will be a tendency for chemico-osmotic liquid flux to develop from the lower concentration (DI water) boundary to the higher concentration boundary (top). However, since there is no space available for this liquid flux to accumulate, chemico-osmotic liquid flux cannot occur, such that a chemico-osmotic pressure difference develops across the specimen to counteract the tendency from chemico-osmotic liquid flux. The chemico-osmotic pressure difference is measured continuously via digital pressure transducers. Membrane efficiency is then calculated as the ratio of the change in chemico-osmotic pressure difference and the maximum possible chemicoosmotic pressure based on the boundary solute concentrations. In addition, $D^{*}$ of the solute can be determined from the diffusive mass flux through the specimen based on the gain in solute mass in the bottom circulating liquid as a function of time.

The ability of Na-B-GCL to restrict solute migration depends on several physical and chemical conditions (e.g. density, type and concentrations of solutes) (Shackelford et al. 2003; Shackelford and Scalia 2016). 


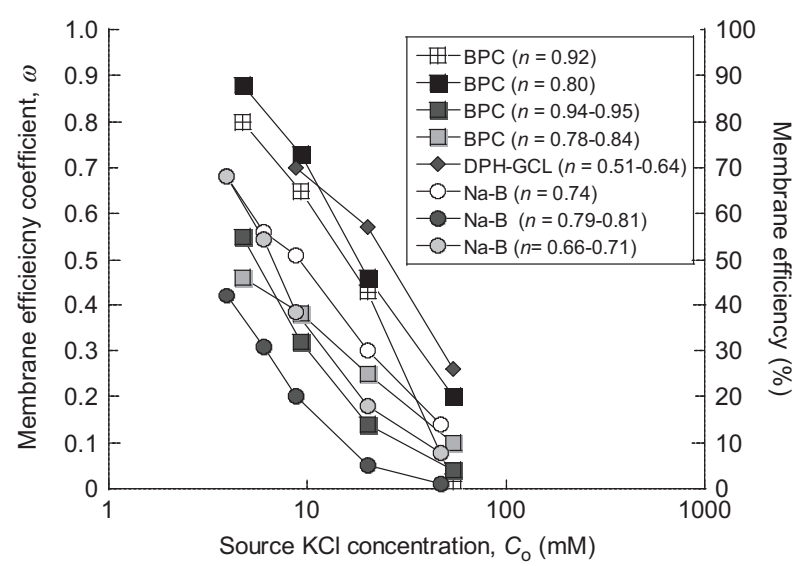

(a)

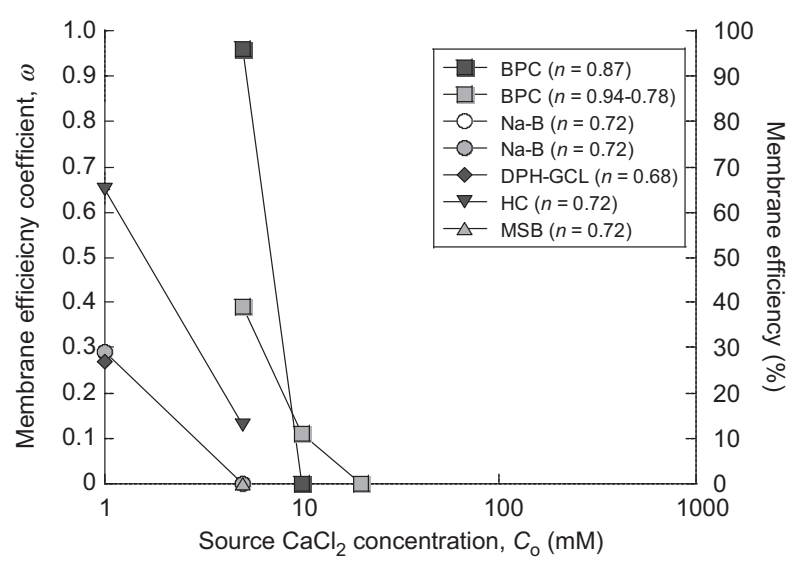

(b)

Figure 11. Membrane efficiency coefficients $(\omega)$ for enhanced bentonites and Na-B versus source concentration (a and $b$, after Bohnhoff $e$ t al. 2016) or versus ionic strength (c)

As indicated in Figure 11, a direct correspondence exists between increases in ionic strength and partial or complete destruction of membrane behavior in Na-B-GCL. However, there is potential for EB-GCL to exhibit more sustainable or persistent membrane behavior (Bohnhoff and Shackelford 2013; Bohnhoff et al. 2014; Meier et al. 2014; Shackelford et al. 2016). In general, $\omega$ is higher for EB-GCLs than Na-B-GCLs at similar $n$ using similar salt solutions (Figure 11). For example, the EB-GCL exposed to $\mathrm{KCl}$ has $\omega$ as high as 0.88 , whereas the maximum $\omega$ for Na-B-GCL was 0.68 . The $\omega$ of GCLs with either $\mathrm{EB}$ or $\mathrm{Na}-\mathrm{B}$ decreased with increasing ionic strength, but the $\omega$ of EB-GCL were still greater than those with Na-B-GCL at the highest ionic strength for specimens tested with $\mathrm{KCl}$ solutions. For example, at ionic strength $\approx 50 \mathrm{mM}, \omega$ of the DPH-GCL is 0.26 whereas the $\omega$ for Na-B-GCL are $\leq 0.14$. For several of the EB-GCLs exposed to $\mathrm{CaCl}_{2}$ (Figure 11b), the membrane behavior persisted $(\omega>0)$ at higher concentrations to a greater extent than exhibited by Na-B-GCLs, where such high salt concentrations caused complete degradation of membrane behavior (i.e. $\omega=0$ ). However, membrane behavior also eventually diminished for the EB-GCL specimens (i.e. MSB-, HC-, BPC-, and DPH-GCL) that were exposed to solutions containing increasingly higher concentrations of $\mathrm{CaCl}_{2}$.

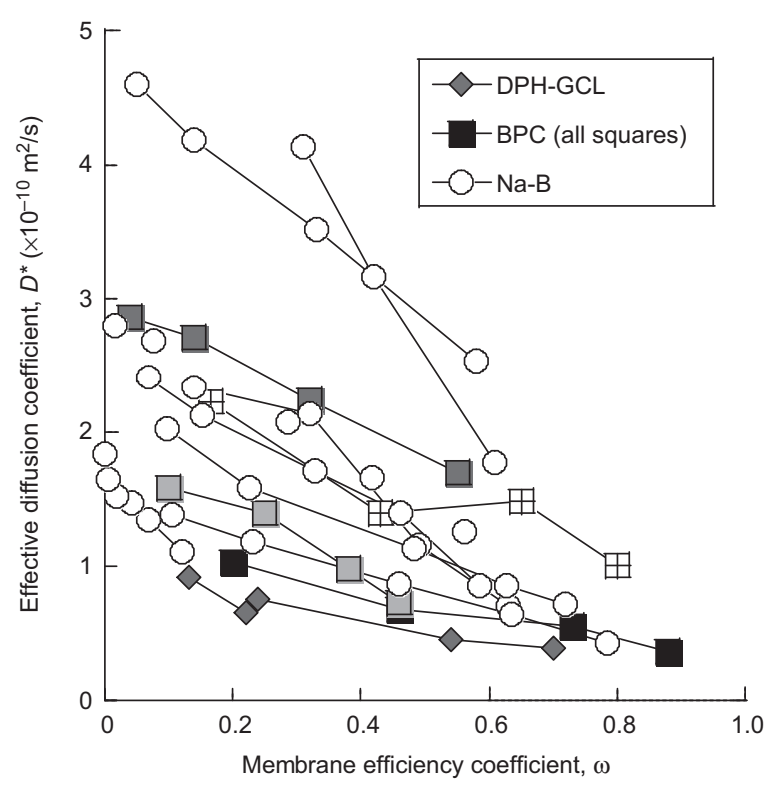

Figure 12. Trends in coupled membrane and diffusive behavior for enhanced bentonites (bentonite-polyacrylic-acid composite, BPC, dense prehydrated geosynthetic clay liner, DPH-GCL) and Na-bentonite (Na-B) for test solutions of KCl

\section{COUPLED MEMBRANE BEHAVIOR AND DIFFUSION}

The $\omega$ for EB-GCL decreased with increasing ionic strength (Figure 11) and the $D^{*}$ for $\mathrm{Cl}^{-}$increased semi-log linearly with increasing ionic strength (Figure 9) for both Na-B- and EB-GCL. The $D^{*}$ can be correlated with the associated $\omega$ for a limited dataset available for EB-GCLs (DPH- and BPC-GCL) and for Na-B-GCL with solutions of $\mathrm{KCl}$ ranging from 4.7 to $400 \mathrm{mM}$ (Figure 12). The $D^{*}$ decreases with increasing $\omega$ for both the EB- and the Na-B-GCL, because solute transport becomes increasingly more restricted as membrane behavior trends toward that of a perfect membrane (i.e. $\omega \rightarrow 1$ ) (e.g. Malusis and Shackelford 2002a).

\section{MECHANISMS}

Mechanisms believed to underlie the hydraulic and chemical transport behavior of EB-GCL are shown schematically in Figure 1. The hypothesized mechanisms governing EB-GCL are grouped into three categories: (1) enhanced osmotic swell by a chemical intercalated within the montmorillonite interlayer; (2) intergranular pore clogging; and (3) prevention of cation exchange. These mechanisms are described subsequently. The mechanisms illustrated in Figure 1 are limited to osmotic swell enhancement (Figures 1e-1h) and pore clogging (Figures 1i-11), due to the apparent dominance of these mechanisms (discussed subsequently).

\subsection{Osmotic swell enhancement}

MSB has been shown to exhibit osmotic swelling over a wider range of concentrations due to osmotic swell at elevated concentrations by the intercalated chemical 
(PC, GC, or Na-CMC) in the montmorillonite interlayer (Figure 1h; Onikata et al. 1996; Fehervari et al. 2016; Gates et al. 2016). HC has been hypothesized to follow a similar mechanism (Di Emidio 2010; Di Emidio et al. 2010). Additional swelling of these materials achieved by intercalating the chemical is hypothesized to result in reduction or elimination of the mobile liquid phase within intergranular pore space (Figure 1f), relegating flow to intragranular pores spaces (Figure 1g), and yielding a lower $k$.

To activate osmotic swelling in solutions that typically preclude such behavior, Onikata et al. (1996) intercalated PC (a high-polarity, aprotic solvent) within the montmorillonite interlayer to form MSB. Onikata et al. (1999) showed that solvent intercalation was driven by interlayer cation solvation, and that these interactions became stronger when cations with larger polymerizing power (e.g. calcium cations have a larger polarizing power than sodium cations) are combined with a greater solvent electron donor ability, yielding more stable complexes (Yamanaka et al. 1974). Similarly, Fehervari et al. (2016) intercalated GC (a higher polarity (than PC) aprotic solvent) and demonstrated that intercalation was driven by interlayer cation solvation. Low-angle X-ray diffraction (XRD) of dried MSB created with PC implied increased $d_{001}$ montmorillonite spacing, illustrative of one or two layers of intercalated PC (Figure 13). Both PC and GC have been demonstrated to coordinate with metal cations in the interlayer via cation-dipole interactions (Onikata et al. 1999; Gates et al. 2016), and when present, through coordination to interlayer cations through the hydration shells of the cations (Onikata et al. 1999). Onikata et al. (1999) showed that intercalated PC increased swelling by expanding the space between adjacent montmorillonite platelets and allowing the activation of osmotic swelling in $\mathrm{NaCl}$ solutions with ionic strength up to $\sim 0.75 \mathrm{M}$, in contrast to solutions up to $\sim 0.3 \mathrm{M}$ for Na-B (Norrish and Quirk 1954). Similar activation of swelling was demonstrated for intercalated

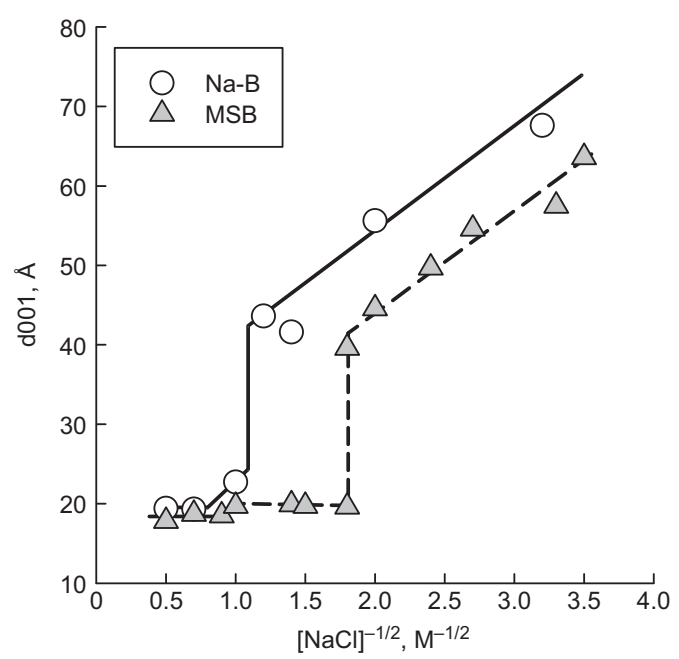

Figure 13. Interlayer swelling of sodium bentonite (Na-B) and multi-swellable bentonite (MSB) with intercalated propylene carbonate (adapted from Onikata et al. 1999)
GC. However, GC intercalates retained greater swelling at high concentrations than PC (Fehervari et al. 2016). The electrostatics of this activation are described for PC by Onikata et al. (1999) and for GC by Gates et al. (2016). Gates et al. (2016) also provide a detailed discussion of the interactions between organic carbonates, interlayer water, and clay lamellae. In addition, Gates et al. (2016) demonstrated that other cyclic organic carbonates (COCs) including 4-(2-hydroxyethyl)-1,3-dioxolan-2-one (HED), and 4-(4-hydroxybutyl)-1,3-dioxolan-2-one (HBD), can yield similar interactions to $\mathrm{PC}$ and $\mathrm{GC}$, and provide greater interlayer separation at similar loading. Gates et al. (2016) notes that other COCs may provide a class of useful swell-maintaining agents (additional research is still needed to assess the engineering properties of bentonite amended with other COCs). In $\mathrm{NaCl}$ solutions with ionic strength $>0.75 \mathrm{M}$, osmotic swell does not occur and only crystalline swell occurs (Onikata et al. 1999). Thus, enhancing osmotic swell by intercalation has a range of concentrations over which this mechanism will yield lower $k$, lower $D^{*}$, and higher $\omega$.

In both HC and DPH-GCLs, XRD has shown that $\mathrm{Na}-\mathrm{CMC}$ is intercalated in the montmorillonite interlayer, and has been hypothesized to act as an osmotic-swell activator similar to PC in MSB (Schroeder et al. 2001; Kolstad et al. 2004b; Katsumi et al. 2008; Di Emidio et al. 2010). Data from swell index tests on HC support this hypothesis (Figure 4). Conversely, larger PAA molecules in BPC are not intercalated (Scalia and Benson 2016), such that this mechanism does not apply to this material. Swell index test data for CRCs published in the literature (Figure 5) do not show increased swelling. Thus, although the additives for these materials are proprietary, they do not appear to function as osmotic swell activators.

\subsection{Pore clogging}

Insensitivity of $k$ of BPC-GCL, HC-GCL, and DPHGCL to SI (Figure 6) suggests that the size of pores in these materials is being restricted independent of swelling. While PAA was originally believed to function by providing supplemental swelling (Trauger and Darlington 2000), PAA swelling is highly sensitive to ionic strength and multivalent cations (Buchholz and Graham 1998). Scalia et al. (2014) and Scalia and Benson (2016) shown that PAA swelling is not a viable mechanism for improving $k$ when BPC-GCL are permeated with high concentration solutions. Physical preconditioning (that is, prehydration and densification) of DPH-GCLs provides a partial explanation for reduced pore sizes, such that SI and $k$ are decoupled for this material (Katsumi et al. 2008). However, BPC- and HC-GCLs are not physically preconditioned.

Clogging of pores by water soluble (low molecular weight) PAA was hypothesized by Scalia et al. (2014) to underlie the decoupling of swelling and $k$ of BPC-GCLs with higher ionic solutions. Tian et al. (2016a, 2016b) report similar decoupling of swell index and $k$ for BPCand CRC-GCLs, and used scanning electron microscopy (SEM) to reveal a network of polymer hydrogel blocking the pore space of a BPC-GCL permeated with DI water. 


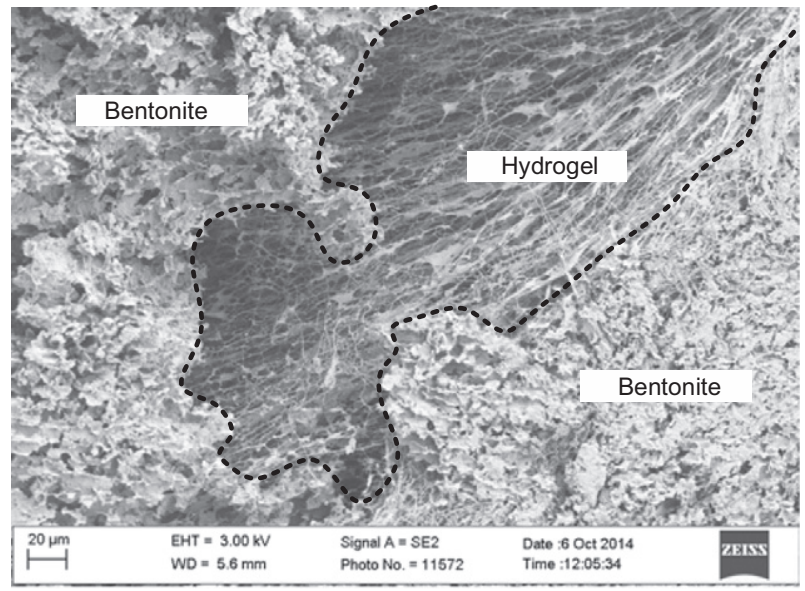

Figure 14. Scanning electron microscope (SEM) images of dehydrated polymer within inter particle pore space of bentonite polyacrylic-acid composite

A similar SEM image obtained for the material based on the methods described in Tian et al. (2016b) is presented in Figure 14. Hydrated polymer hydrogel is hypothesized to occlude intergranular pores, constraining flow through more narrow and tortuous intragranular flow paths (conceptually illustrated in Figures $1 \mathrm{j}$ and $1 \mathrm{k}$ ), resulting in lower $k$ and $D^{*}$, and higher $\omega$.

Possible binding mechanisms between the poreclogging polymer and the bentonite minerals surfaces, such as attachment of an anionic polymer to the montmorillonite surface by cation bridging, are hypothesized by Scalia et al. (2014), Tian et al. (2016b), and Scalia and Benson (2017), but have not been investigated or demonstrated. The relative contribution of viscosity effects from water soluble PAA or polymer hydrogels is also unknown. The quantity of water-soluble PAA or polymer hydrogel needed to clog pores is unknown (Scalia and Benson 2016; Tian et al. 2016b), but has been demonstrated to be a function of permeant chemistry (Scalia and Benson 2016; Tian et al. 2016b). High $k$ in many CRC-GCLs may be attributable to insufficient additive or elution of the polymer additive during permeation if pore clogging is governing. Scalia and Benson (2016) and Tian et al. (2016b) also suggest that heterogeneity induced by insufficient mixing (Scalia and Benson 2016; Tian et al. 2016b) can contribute to high $k$.

Although osmotic swell enhancement has been reported as the improvement mechanism for $\mathrm{HC}-\mathrm{GCL}$ (Di Emidio et al. 2010), the lack of correlation between swell index and $k$ (Figure 6) for the HC-GCL implies that pore clogging also may be important in HC-GCLs. However, the occurrence, or significance, of pore clogging in HC-GCL is unknown.

\subsection{Prevention of cation exchange}

Using additives to prevent cation exchange has been hypothesized as a mechanism responsible for the low $k$ of some EBs (e.g. Flynn and Carter 1998; Trauger and Darlington 2000). For example, Flynn and Carter (1998) state that addition of $8-16 \%$ PAA along with $\mathrm{Na}-\mathrm{CMC}$ inhibits ion exchange and renders the cation exchange capacity of the modified bentonite 'nil or very low'. Trauger and Darlington (2000) hypothesize similar behavior for BPC-GCLs. Scalia et al. (2014) and Benson et al. (2014) report nearly complete cation exchange in BPC-GCLs containing PAA, and Tian et al. (2016a, 2016b) report nearly complete cation exchange for multiple CRC-GCLs. Additionally, preventing cation exchange does not preclude the loss of swell, and associated increases in $k$, associated with elevated concentrations. Thus, existing evidence does not support the prevention of cation exchange as a potential mechanism underlying observed EB-GCL behavior.

\section{LONG-TERM STABILITY}

Limited data are available as to the physical and chemical stability of EB-GCL modifying agents under field conditions. For example, the effects of wet-dry cycling, freeze-thaw cycling, microbial activity, temperature fluctuations, and chemical degradation on EB-GCLs is unknown. Mazzieri et al. (2010a) show that PC is eluted from MSB-GCLs during prehydration with dilute permeant solution. Mazzieri et al. (2017) demonstrated MSB- and DPH-GCLs are susceptible to increases in $k$ when subjected to wet-dry cycling (similar behavior has been extensively demonstrated for Na-B GCLs, e.g. Benson and Meer 2009), and that the wet-dry aging process appeared to have extracted the amending polymers from both materials. De Camillis et al. (2016a, 2016b) show that $k$ of a HC-GCL increased when subject to wet-dry cycling, but the increase was smaller than for $\mathrm{Na}-\mathrm{B}$ tested under equivalent conditions. Additional research is needed to understand the long-term stability of EB-GCL modifying agents under field conditions.

\section{CONCLUSIONS AND RECOMMENDATIONS}

An overview of GCLs containing enhanced bentonites (EBs), or EB-GCLs, engineered to minimize chemical transport processes in environmental containment applications has been presented. The overview includes a summary and evaluation of the parameters governing contaminant transport, including the hydraulic conductivity, $k$, the effective diffusion coefficient, $D^{*}$, and the membrane or chemico-osmotic membrane efficiency coefficient, $\omega$, the applicability of existing indicator parameters for $k$, specifically the swell index, SI, fluid loss, FL, and liquid limit, LL, and the potential underlying mechanisms. The conclusions and recommendations derived from this overview are as follows.

- EB-GCLs generally exhibit lower $k$, lower $D^{*}$, higher $\omega$ than sodium bentonite (Na-B) GCLs when exposed to similar conditions (solution chemistry, physical condition). Contaminant resistant clay (CRC) GCLs may have higher or lower $k$ and $D^{*}$ than Na-B GCLs under similar conditions. 
- Traditional index properties (SI, FL, LL) may not be reliable to assess whether EBs will have low $k$, such that hydraulic compatibility tests are necessary. These indicator parameters may still be viable for EB-GCLs where swelling is the primary mechanism responsible for low $k$, - for example, multi-swellable bentonite (MSB), including bentonite amended with glycerol carbonate.

- EB-GCLs have lower $D^{*}$ relative to Na-B-GCLs for a given ionic strength.

- EB-GCLs have higher $\omega$ relative to Na-B-GCL for a given ionic strength.

Additional research is needed to understand the mechanisms underlying the superior properties for containment systems containing EB-GCLs. Existing data support enhanced properties of MSB, and $\mathrm{HC}$ derived from activation of osmotic swelling, and BPC as well as possibly HC and CRCs derived from pore clogging. However, the mechanisms and performance thresholds of pore clogging are not well understood and need more study. Methods are needed for index property tests on EB-GCLs for which swelling does not govern $k$. Additional research is also needed to understand the physical and chemical stability of EB-GCL modifying agents under field conditions.

\section{NOTATION}

Basic SI units are given in parentheses.

$c_{i} \quad$ concentration of ionic species I (M)

$\begin{aligned} D^{*} & \text { effective diffusion coefficient }(\mathrm{m} / \mathrm{s}) \\ \mathrm{EC} & \text { electrical conductivity }(\mathrm{S} / \mathrm{m}) \\ \mathrm{FL} & \text { fluid loss }\left(\mathrm{m}^{3}\right) \\ I & \text { ionic strength }(\mathrm{M}) \\ i & \text { ionic species (dimensionless) } \\ k & \text { hydraulic conductivity }\left(\mathrm{m}^{2} / \mathrm{s}\right) \\ \mathrm{LL} & \text { liquid limit (dimensionless) } \\ n & \text { porosity (dimensionless) } \\ \mathrm{MD} & \text { ratio of monovalent to divalent cations } \\ & \text { (dimensionless) } \\ \mathrm{SI} & \left.\text { swell index ( }{ }^{3} / \mathrm{kg}\right) \\ z_{i} & \text { charge of ionic species } i \text { (dimensionless) } \\ \sigma^{\prime} & \text { effective stress }(\mathrm{Pa}) \\ \omega & \text { chemico-osmotic efficiency coefficient } \\ & \text { (dimensionless) }\end{aligned}$

\section{ABBREVIATIONS}

BPC bentonite-polyacrylic-acid composite

COC cyclic organic carbonates

CRC contaminant resistant clay

DPH-GCL dense-prehydrated geosynthetic clay liner

DI deionized (water)

EB enhanced bentonite

GCL geosynthetic clay liner

HC HYPER clay

MSB multi-swellable bentonite
Na-B sodium bentonite

SEM scanning electron microscopy

XRD X-ray diffraction

\section{REFERENCES}

Arndt, G., Adams, G., Jung, A. \& Goldenberg, M. (2015). Chemical compatibility of a polymer-modified GCL. Proceedings, Geosynthetics Conference 2015, Portland, Oregon, Industrial Fabrics Association International, Roseville, MN, USA, pp. 1254-1262.

Arndt, D., Mattei, M., Heist, C. \& McGuire, M. (2017). Measurement of swelling of individual smectite tactoids in situ using atomic force microscopy. Clays and Clay Minerals, 65, No. 2, 92-103.

Ashmawy, A., Darwish, E., Sotelo, N. \& Muhammad, N. (2002). Hydraulic performance of untreated and polymer-treated bentonite in inorganic landfill leachates. Clays and Clay Minerals, 50, No. 5, 546-552.

ASTM D4318 Standard Test Methods for Liquid Limit, Plastic Limit, and Plasticity Index of Soils, ASTM International, West Conshohocken, PA, USA.

ASTM D2487 Standard Practice for Classification of Soils for Engineering Purposes (Unified Soil Classification System), ASTM International, West Conshohocken, PA, USA.

ASTM D5890 Standard Test Method for Swell Index of Clay Mineral Component of Geosynthetic Clay Liners, ASTM International, West Conshohocken, PA, USA.

ASTM D5891 Standard Test Method for Fluid Loss of Clay Component of Geosynthetic Clay Liners, ASTM International, West Conshohocken, PA, USA.

Athanassopoulos, C., Benson, C., Donovan, M. \& Chen, J. (2015). Hydraulic conductivity of a polymer-modified GCL permeated with high-pH solutions. Proceedings, Geosynthetics Conference 2015, Portland, Oregon, Industrial Fabrics Association International, Roseville, MN, USA, pp. 181-186.

Ben Rhaiem, C., Pons, C. \& Tessier, D. (1987). Factors affecting the microstructure of smectites: role of cation and history of applied stress. Proceedings of the International Clay Conference, Denver, 1985, Denver, CO, USA, Schultz, L., van Olphen, H. \& Mumpton, F., Editors, The Clay Minerals Society, Bloomington, IN, USA, pp. 292-297.

Benson, C. \& Meer, S. (2009). Relative abundance of monovalent and divalent cations and the impact of desiccation on geosynthetic clay liners. Journal of Geotechnical and Geoenvironmental Engineering, 133, No. 5, 814-827.

Benson, C., Oren, A. \& Gates, W. (2010a). Hydraulic conductivity of two geosynthetic clay liners permeated with a hyperalkaline solution. Geotextiles and Geomembranes, 28, No. 2, 206-218.

Benson, C., Kucukkirca, E. \& Scalia, J. (2010b). Properties of geosynthetics exhumed from a final cover at a solid waste landfill. Geotexttiles and Geomembranes, 28, No. 6, 536-546.

Benson, C., Chen, J. \& Edil, T. (2014). Engineering Properties of Geosynthetic Clay Liners Permeated with Coal Combustion Product Leachates, Report No. 3002003770. Electric Power Research Institute (EPRI), Palo Alto, CA, USA.

Bohnhoff, G. \& Shackelford, C. (2013). Improving membrane performance via bentonite polymer nanocomposite. Applied Clay Science, 86, 83-98.

Bohnhoff, G. \& Shackelford, C. (2014). Hydraulic conductivity of chemically modified bentonites for containment barriers Proceedings, 7th International Conference on Environmental Geotechnics, Melbourne, Australia, Bouazza, A., Yuen, S. \& Brown, B., Editors, Engineers Australia, Melbourne, Australia, pp. 440-447. ISBN 978-1-922107-23-7.

Bohnhoff, G., Shackelford, C., Malusis, M., Scalia, J., Benson, C., Edil, T., Di Emiddio, G., Katsumi, T. \& Mazzieri, F. (2013). Novel bentonites for containment barrier applications. Proceedings, 18th International Conference on Soil Mechanics and Geotechnical Engineering-Challenges and Innovations in Geotechnics, Paris, 
France, Delage, P., Desrues, J., Frank, R., Puech, A. \& Schlosser, F., Editors, Presses des Ponts, Paris, France, vol. 4, pp. 2997-3000.

Bohnhoff, G., Shackelford, C. \& Sample-Lord, K. (2014). Calcium resistant membrane behavior of a polymerized bentonite. Journal of Geotechnical and Geoenvironmental Engineering, 140, No. 3, 04013029.

Bohnhoff, G., Sample-Lord, K. \& Shackelford, C. (2016). Advances in membrane behavior of bentonite-based barriers. Geo-Chicago 2016: Sustainable Geoenvironmental Systems, Chicago, IL, USA, De, A., Reddy, K. R., Yesiller, N., Zekkos, D. \& Farid, A., Editors, Geotechnical Special Publication No. 271, ASCE, Reston, VA, USA, pp. 329-338.

Bouazza, A. (2010). Geosynthetics lining in mining applications. Proceedings of Sixth International Conference on Environmental Geotechnics, New Delhi, India, International Society for Soil Mechanics and Geotechnical Engineers, New Delhi, India, pp. 221-259.

Bouazza, A. \& Bowders, J. (2010). Geosynthetic Clay Liners in Waste Containment Facilities. CRC Press/Balkema, Leiden, the Netherlands.

Bouazza, A. \& Gates, W. (2014). Overview of performance compatibility issues of GCLs with respect to leachates of extreme chemistry. Geosynthetics International, 21, No. 2, 151-167.

Bradshaw, S. \& Benson, C. (2014). Effect of municipal solid waste leachate on hydraulic conductivity and exchange complex of geosynthetic clay liners. Journal of Geotechnical and Geoenvironmental Engineering, 140, No. 4, 04013038.

Buchholz, F. \& Graham, A. (1998). Modern Superabsorbent Polymer Technology. John Wiley and Sons, New York, NY, USA.

Chen, J., Bradshaw, S., Likos, W., Benson, C. \& Edil, T. (2014). Hydraulic conductivity of geosynthetic clay liners to synthetic coal combustion product leachates. Geo-Characterization and Modeling for Sustainability, Geo-Congress, Atlanta, GA, USA, Geotechnical Special Publication No. 234, ASCE, Reston, VA, USA, pp. 334-342.

Chen, J., Benson, C., Edil, T. \& Likos, W. (2018). Hydraulic conductivity of geosynthetic clay liners with sodium bentonite to coal combustion product leachates. Journal of Geotechnical and Geoenvironmental Engineering, 144, No. 3, https://doi.org/ 10.1061/(ASCE)GT.1943-5606.0001844.

Chung, J. \& Daniel, D. (2008). Modified fluid loss test as an improved measure of hydraulic conductivity for bentonite. Geotechnical Testing Journal, 31, No. 3, 243-251.

De Camillis, M., Di Emidio, G., Verastegui-Flores, D. \& Bezuijen, A. (2014). Polymer treated clays subjected to wet-dry cycling with seawater. Proceedings of the 7th International Congress on Environmental Geotechnics (ICEG7 2014), Melbourne, Australia, pp. 1002-1008.

De Camillis, M., De Emidio, G., Bezuijen, A. \& Verastegui-Flores, D. (2016a). Wet and dry effects on the hydraulic conductivity of a polymer treated GCL prototype. Proceedings, Geo-Chicago 2016, Chicago, IL, USA, GSP No. 271, ASCE, Reston, VA, USA, pp. 518-527.

De Camillis, M., De Emidio, G., Bezuijen, A. \& Verastegui-Flores, D. (2016b). Hydraulic conductivity and swelling ability of a polymer modified bentonite subjected to wet-dry cycles in seawater. Geotextiles and Geomembranes, 44, 739-747.

Di Emidio, G. (2010). Hydraulic and Chemico-Osmotic Performance of Polymer Treated Clays. PhD dissertation, Universiteit Gent, Ghent, Belgium.

Di Emidio, G., Van Impe, W. \& Mazzieri, F. (2010). A polymer enhanced clay for impermeable geosynthetic clay liners. Proceedings of Sixth International Conference on Environmental Geotechnics, New Delhi, India, International Society for Soil Mechanics and Geotechnical Engineers, New Delhi, India, pp. 963-967.

Di Emidio, G., Van Impe, W. \& Flores, V. (2011). Advances in geosynthetic clay liners: polymer enhanced clays. GeoFrontiers 2011. Advances in Geotechnical Engineering, Dallas, TX, USA, American Society of Civil Engineers, Reston, USA, pp. 1931-1940.
Di Emidio, G., Mazzieri, F., Verastegui-Flores, R., Van Impe, W. \& Bezuijen, A. (2015). Polymer-treated bentonite clay for chemicalresistant geosynthetic clay liners. Geosynthetics International, 22, No. 1, 125-137.

Fehervari, A., Gates, W., Patti, A., Turney, T., Bouazza, A. \& Rowe, R. (2016). Potential hydraulic barrier performance of cyclic organic carbonate modified bentonite complexes against hyper-salinity. Geotextiles and Geomembranes, 44, No. 5, 748-760.

Flynn, B. \& Carter, G. (1998). Waterproofing Material and Method of Fabrication Thereof. US Patent Number: 6,537,676 B1, Mar.

Foose, G., Benson, C. \& Edil, T. (2002). Comparison of solute transport in three composite liners. Journal of Geotechnical and Geoenvironmental Engineering, 125, No. 5, 391-403.

Gates, W. \& Bouazza, A. (2010). Bentonite transformations in strongly alkaline solutions. Geotextiles and Geomembranes, 28, No. 2, 219-225.

Gates, W., Shaheen, U., Turney, T. \& Patti, A. (2016). Cyclic carbonate-sodium smectite intercalates. Applied Clay Science, 124-125, 94-101.

GI (Geosynthetic Institute) (2016). GRI test method GCL3: Test Methods, Required Properties, and Testing Frequencies of Geosynthetic Clay Liners (GCLs). Geosynthetic Institute, Folsom, PA, USA.

Goldenberg, M. \& Reddy, K. (2016). Evaluation of prototype geosynthetic clay liners in landfill applications. Proceedings, Geo-Chicago 2016, Chicago, IL, USA, GSP No. 271, ASCE, Reston, VA, USA, pp. $398-407$.

Griffin, R. \& Jurinak, J. (1973). Estimation of activity coefficient from electrical conductivity of natural aquatic systems and soil extracts. Soil Science, 116, No. 1, 26-30.

Grim, R. (1968). Clay Mineralogy, 2nd edn. McGraw-Hill, New York, NY, USA.

Guyonnet, D., Cazaux, D., Vigier-Gailhanou, H. \& Chevrier, B. (2009). Effect of cation exchange on hydraulic conductivity in a sand-bentonite-polymer-mixture. Proceedings, Sardinia 2009, 12th International Waste Management and Landfill Symposium, Pula, Italy, Environmental Sanitary Engineering Centre (CISA), Cagliari, Italy.

Hornsey, W., Schers, J., Gates, W. \& Bouazza, A. (2010). The impact of mining solutions/liquors on geosynthetics. Geotextiles and Geomembranes, 28, No. 2, 191-198.

Janssen, J., Di Emidio, G., Verastegui Flores, R. \& Bezuigen, A. (2015). Hydraulic conductivity and swelling pressure of GCLs using polymer treated clays to high concentration $\mathrm{CaCl}_{2}$ solutions. Geotechnical Engineering for Infrastructure Development. Proceedings of the XVI European Conference for Soil Mechanics and Geotechnical Engineering, Edinburgh, UK, Institute of Civil Engineers, London, UK, pp. 2687-2692.

Jo, H., Katsumi, T., Benson, C. \& Edil, T. (2001). Hydraulic conductivity and swelling of non-prehydrated GCLs permeated with single species salt solutions. Journal of Geotechnical and Geoenvironmental Engineering, 127, No. 7, 557-567.

Jo, H., Benson, C. \& Edil, T. (2004). Hydraulic conductivity and cation exchange in non-prehydrated and prehydrated bentonite permeated with weak inorganic salt solutions. Clays and Clay Minerals, 52, No. 6, 661-679.

Jo, H., Benson, C., Shackelford, C., Lee, J. \& Edil, T. (2005). Long-term hydraulic conductivity of a non-prehydrated geosynthetic clay liner permeated with inorganic salt solutions. Journal of Geotechnical and Geoenvironmental Engineering, 131, No. 4, 405-417.

Jo, H., Benson, C. \& Edil, T. (2006). Rate-limited cation exchange in thin bentonitic barrier layers. Canadian Geotechnical Journal, 43, No. 4, 370-391.

Kang, J. \& Shackelford, C. (2011). Consolidation enhanced membrane behavior of a geosynthetic clay liner. Geotextiles and Geomembranes, 29, No. 6, 544-556.

Katsumi, T., Ishimori, H., Onikata, M. \& Fukagawa, R. (2008). Long-term barrier performance of modified bentonite materials against sodium and calcium permeant solutions. Geotextiles and Geomembranes, 26, No. 1, 14-30. 
Kolstad, D., Benson, C. \& Edil, T. (2004a). Hydraulic conductivity and swell of nonprehydrated GCLs permeated with multi-species inorganic solutions. Journal of Geotechnical and Geoenvironmental Engineering, 130, No. 12, 1236-1249.

Kolstad, D., Benson, C., Edil, T. \& Jo, H. (2004b). Hydraulic conductivity of dense prehydrated GCL permeated with aggressive inorganic solutions. Geosynthetics International, 11, No. 3, pp. 233-241.

Lee, J. \& Shackelford, C. (2005a). Impact of bentonite quality on hydraulic conductivity of geosynthetic clay liners. Journal of Geotechnical and Geoenvironmental Engineering, 131, No. 1, 64-77.

Lee, J. \& Shackelford, C. (2005b). Solution retention capacity as an alternative to the swell index test for sodium bentonite. Geotechnical Testing Journal, 28, No. 1, 61-70.

Lee, J., Shackelford, C., Benson, C., Jo, H. \& Edil, T. (2005). Correlating index properties and hydraulic conductivity of geosynthetic clay liners. Journal of Geotechnical and Geoenvironmental Engineering, 131, No. 11, 1319-1329.

Likos, W. \& Wayllace, A. (2010). Porosity evolution of free and confined bentonites during interlayer hydration. Clays and Clay Minerals, 58, No. 3, 399-414.

Lin, L., Katsumi, T., Kamon, M., Benson, C., Onikata, M. \& Kondo, M. (2000). Evaluation of chemical-resistant bentonite for landfill barrier applications. Annuals of Disaster Prevention Research Institute, No. 43 B-2, 525-533.

Liu, Y., Gates, W., Bouazza, A. \& Rowe, K. (2013). Fluid loss as a quick method to evaluate hydraulic conductivity of geosynthetic clay liners under acidic conditions. Canadian Geotechnical Journal, 51, No. 2, 158-163.

Malusis, M. \& Daniyarov, A. (2016). Membrane efficiency and diffusive tortuosity of dense Prehydrated geosynthetic clay liner. Geotextiles and Geomembranes, 44, No. 5, 719-730, https://doi.org/10.1016/ j.geotexmem.2016.05.006.

Malusis, M. \& Shackelford, C. (2002a). Coupling effects during steady-state solute diffusion through a semipermeable clay membrane. Environmental Science \& Technology, 36, No. 6, 1312-1319.

Malusis, M. \& Shackelford, C. (2002b). Chemico-osmotic efficiency of a geosynthetic clay liner. Journal of Geotechnical and Geoenvironmental Engineering, 128, No. 2, 97-106.

Malusis, M., Shackelford, C. \& Olsen, H. (2001). A laboratory apparatus to measure chemico-osmotic efficiency coefficients for clay soils. Geotechnical Testing Journal, 24, No. 3, 229-242.

Malusis, M., Shackelford, C. \& Olsen, H. (2003). Flow and transport through clay membrane barriers. Engineering Geology, 70, No. 3-4, 235-248.

Malusis, M., Kang, J. \& Shackelford, C. (2015). Restricted salt diffusion in a geosynthetic clay liner. Environmental Geotechnics, 2, No. 2, 68-77, https://doi.org/10.1680/envgeo.13.00080.

Mazzieri, F. \& Di Emidio, G. (2015). Hydraulic conductivity of a dense prehydrated geosynthetic clay liner. Geosynthetics International, 22, No. $1,138-148$

Mazzieri, F. \& Pasqualini, E. (2006). Evaluating the permeability of an organically modified bentonite to natural seawater. Proceedings of Fifth International Conference on Environmental Geotechnics, Cardiff, Wales, UK, International Society for Soil Mechanics and Geotechnical Engineers, Valencia, Spain, pp. 749-756.

Mazzieri, F. \& Pasqualini, E. (2011). Retention of heavy metals in conventional and factory-prehydrated GCL materials. GeoFrontiers 2011. Advances in Geotechnical Engineering, Dallas, TX, USA, American Society of Civil Engineers, Reston, USA, pp. 1941-1950, https://doi.org/10.1061/41165(397)198.

Mazzieri, F., Di Emidio, G. \& Van Impe, P. (2010a). Diffusion of calcium chloride in a modified bentonite: impact on osmotic efficiency and hydraulic conductivity. Clays and Clay Minerals, 58, No. 3, 351-363.

Mazzieri, F., Pasqualini, E. \& Emidio, G. (2010b). Migration of heavy metals through conventional and factory-prehydrated GCL materials. Proceedings of Sixth International Conference on Environmental Geotechnics, New Delhi, India, International Society for Soil Mechanics and Geotechnical Engineers, New Delhi, India, pp. 963-967.
Mazzieri, F., Di Emidio, G. \& Pasqualini, E. (2017). Effect of wet-and-dry ageing in seawater on the swelling properties and hydraulic conductivity of two amended bentonites. Applied Clay Science, 142, No. 15, 40-51.

McBride, M. (1994). Environmental Chemistry of Soils. Oxford University Press, New York, NY, USA

McRory, J. \& Ashmawy, A. (2005). Polymer treatment of bentonite clay for contaminant resistant barriers. Geo-Frontiers Congress 2005, Austin, TX, USA, GSP 142 Waste Containment and Remediation, pp. $1-11$.

Meer, S. \& Benson, C. (2007). Hydraulic conductivity of geosynthetic clay liners exhumed from landfill final covers. Journal of Geotechnical and Geoenvironmental Engineering, 133, No. 5, 550-563.

Meier, A., Sample-Lord, K., Castelbaum, D., Kallase, S., Moran, B., Ray, T. \& Shackelford, C. (2014). Persistence of semipermeable membrane behavior for a geosynthetic clay liner. Proceedings, 7th International Conference on Environmental Geotechnics, Melbourne, Australia, Engineers Australia, Melbourne, Australia, pp. 496-503. ISBN 978-1-922107-23-7.

Mesri, G. \& Olson, R. (1971). Mechanisms controlling the permeability of clays. Clay and Clay Minerals, 19, 151-158.

Norrish, K. (1954). The swelling of montmorillonite. Discussions of the Faraday Society, 18, 120-134.

Norrish, K. \& Quirk, J. (1954). Crystalline swelling of montmorillonite, use of electrolytes to control swelling. Nature, 173, 255-257.

Onikata, M., Kondo, M. \& Kamon, M. (1996). Development and characterization of a multiswellable bentonite. Proceedings of the 2nd International Congress on Environmental Geotechnics, Osaka, Japan, Balkema, Rotterdam, the Netherlands, pp. 587-590.

Onikata, M., Kondo, M., Hayashi, N. \& Yamanaka, S. (1999). Complex formation of cation-exchanged montmorillonites with propylene carbonate: Osmotic swelling in aqueous electrolyte solutions. Clays and Clay Minerals, 47, No. 5, 672-677.

Quirk, J. \& Aylmore, A. (1971). Domains and quasi-crystalline regions in clay systems. Soil Science Society of America Proceedings, 35, 652-654.

Rosin-Paumier, S., Touze-Foltz, N., Pantet, A., Monnet, P., Didier, G., Guyonnet, D. \& Norotte, V. (2010). Swell index, oedopermeametric, filter press and rheometric tests for identifying the qualification of bentonites used in GCLs. Geosynthetics International, 17, No. 1, 1-11.

Saiyouri, N., Tessier, D. \& Hicher, P. (2004). Experimental study of swelling in unsaturated compacted clays. Clay Minerals, 39, No. 4, 469-479.

Salihoglu, H., Chen, J., Likos, W. \& Benson, C. (2016). Hydraulic conductivity of bentonite-polymer geosynthetic clay liners in coal combustion product leachates. Proceedings, Geo-Chicago 2016, Chicago, IL, USA, GSP No. 271, ASCE, Reston, VA, USA, pp. 438-447.

Salles, F., Beurroies, I., Bildstein, O., Jullien, M., Raynal, J., Denoyel, R. \& Van Damme, H. (2008). A calorimetric study of mesoscopic swelling and hydration sequence in solid Na-montmorillonite. Applied Clay Science, 39, No. 3-4, 186-201.

Salles, F., Douillard, J., Denoyel, R., Bildstein, O., Jullien, M., Beurroies, I. \& Van Damme, H. (2009). Hydration sequence of swelling clays: evolutions of specific surface area and hydration energy. Journal of Colloid and Interface Science, $\mathbf{3 3 3}$, $510-522$.

Salles, F., Bildstein, O., Douillard, J., Jullien, M., Raynal, J. \& Van Damme, H. (2010). On the cation dependence of interlamellar and interparticular water and swelling in smectite clays. Langmuir, 26, No. 7, 5028-5037.

Sample-Lord, K. \& Shackelford, C. (2014). Membrane behavior of unsaturated bentonite barriers. Proceedings, Geo-Congress 2014, Atlanta, GA, USA, GSP No. 234, ASCE, Reston, VA, USA, pp. $1900-1909$.

Sample-Lord, K. \& Shackelford, C. (2018). Membrane behavior of unsaturated sodium bentonite. Journal of Geotechnical and Geoenvironmental Engineering, ASCE, 144, No. 1, https://doi.org/ 10.1061/(ASCE)GT.1943-5606.0001803. 
Scalia, J. \& Benson, C. (2011). Hydraulic conductivity of geosynthetic clay liners exhumed from landfill final covers with composite barriers. Journal of Geotechnical and Geoenvironmental Engineering, 137, No. 1, 1-13.

Scalia, J. \& Benson, C. (2014). Barrier performance of bentonitepolyacrylate nanocomposite to artificial ocean water. Proceedings, Geo-Congress 2014 Geo-Characterization and Modeling for Sustainability, GSP No. 234, ASCE, Reston, VA, USA.

Scalia, J. \& Benson, C. (2016). Evaluation of Na-bentonite-polyacrylate mixtures to enhance the chemical resistance of geosynthetic clay liners. Proceedings, Geo-Chicago 2016, Chicago, IL, USA, GSP No. 271, ASCE, Reston, VA, USA.

Scalia, J. \& Benson, C. (2017). Polymer fouling and hydraulic conductivity of mixtures of sodium bentonite and a bentonitepolymer composite. Journal of Geotechnical and Geoenvironmental Engineering, 143, No. 4, https://doi.org/10.1061/(ASCE)GT.19435606.0001628

Scalia, J., Benson, C., Bohnhoff, G., Edil, T. \& Shackelford, C. (2011). Geosynthetic clay liners containing bentonite polymer nanocomposite. Proceedings, Geo-Frontiers 2011. Advances in Geotechnical Engineering, GSP No. 211, ASCE, Reston, VA, USA, pp. 2001-2009.

Scalia, J., Benson, C., Bohnhoff, G., Edil, T. \& Shackelford, C. (2014). Long-term hydraulic conductivity of a bentonite-polymer composite permeated with aggressive inorganic solutions. Journal of Geotechnical and Geoenvironmental Engineering, 140, No. 3, $1-13$.

Schroeder, C., Monjoie, A., Illing, P., Dosquet, D. \& Thorez, J. (2001). Testing a factory-prehydrated GCL under several conditions. Proceedings, Sardinia 2001, 8th International Waste Management and Landfill Symposium, Pula, Italy, CISA Environmental Sanitary Engineering Centre, Cagliari, Italy, pp. 187-196.

Segad, M., Jonsson, B. \& Cabane, B. (2012). Tactoid formation in montmorillonite. Journal of Physical Chemistry, 116, No. 48, 25425-25433.

Shackelford, C. (2013). Membrane behavior in engineered bentonitebased containment barriers: state of the art. Proceedings of Coupled Phenomena in Environmental Geotechnics (CPEG), Torino, Italy, Manassero, M., Dominijanni, A., Foti, S. \& Musso, G., Editors, CRC Press/Balkema, Taylor \& Francis Group, London, UK, pp. $45-60$.

Shackelford, C. (2014). The ISSMGE Kerry Rowe Lecture: The role of diffusion in environmental geotechnics. Canadian Geotechnical Journal, 51, No. 11, 1219-1242.

Shackelford, C. \& Daniel, D. (1991). Diffusion in saturated soil. 1. Background. Journal of Geotechnical Engineering, 117, No. 3, 467-484.

Shackelford, C. \& Lee, J. (2003). The destructive role of diffusion on clay membrane behavior. Clays and Clay Minerals, 51, No. 2, 186-197.

Shackelford, C. \& Scalia, J. (2016). Semipermeable membrane behavior in bentonite-based barriers: past, present, and future. GEOVANCOUVER 2016, Vancouver, Canada, Canadian Geotechnical Society, Richmond, British Columbia, Canada, paper 4173.

Shackelford, C., Malusis, M., Majeski, M. \& Stern, R. (1999). Electrical conductivity breakthrough curves. Journal of Geotechnical and Geoenvironmental Engineering, 125, No. 4, 260-270.

Shackelford, C., Benson, C., Katsumi, T., Edil, T. \& Lin, L. (2000). Evaluating the hydraulic conductivity of GCLs permeated with non-standard liquids. Geotextiles and Geomembranes, 18, No. 2-3, $133-161$.
Shackelford, C., Malusis, M. \& Olsen, H. (2003). Clay membrane behavior for geoenvironmental containment. Soil and Rock America Conference 2003 (Proceedings of the joint 12th Panamerican Conference on Soil Mechanics and Geotechnical Engineering and the 39th U. S. Rock Mechanics Symposium), Cambridge, MA, USA, Culligan, P.J., Einstein, H.H. \& Whittle, A.J., Editors, Verlag Glückauf GMBH, Essen, Germany, vol. 1, pp. 767-774.

Shackelford, C., Sevick, G. \& Eykholt, G. (2010). Hydraulic conductivity of geosynthetic clay liners to tailings impoundment solutions. Geotextiles and Geomembranes, 28, No. 2, 149-162.

Shackelford, C., Meier, A. \& Sample-Lord, K. (2016). Limiting membrane and diffusion behavior of a geosynthetic clay liner. Geotextiles and Geomembranes, 44, No. 5, 707-718.

Shan, H. \& Daniel, D. (1991). Results of laboratory tests on a geotextile/bentonite liner material. Proceedings, Geosynthetics '91, Verlag Glückauf GMBH, Essen, Germany, vol. 2, Industrial Fabrics Association International, St. Paul, MN, USA, pp. $517-535$.

Shomer, I. \& Mingelgrin, U. (1978). A direct procedure for determining the number of plates in tactoids of smectites: the Na/Ca-montmorillonite case. Clays and Clay Minerals, 26, No. 2, $135-138$.

Snoeyink, V. \& Jenkins, D. (1980). Water Chemistry, Wiley, New York, NY, USA.

Stumm, W. \& Morgan, J. (1996). Aquatic Chemistry, 3rd edn. Wiley, New York, NY, USA.

Tessier, D. (1990). Chapter 14: behavior and macrostructure of clay minerals. Soil Colloids and Their Associations in Aggregates, De Boodt, M., Hayes, Y., Herbillon, A., De Strooper, E. \& Tuck, J., Editors, Plenum Press, New York, NY, USA, pp. 387-415.

Tessier, D. \& Pedro, G. (1982). Electron microscopy study of Na smectite fabric - role of layer charge, salt concentration and suction parameters. Proceedings of the International Clay Conference, Bologna and Pavia, Italy, van Olphen, H. \& Veniale, F., Editors, Elsevier Scientific Publishing Company, Amsterdam, the Netherlands, pp. 165-176.

Tian, K. \& Benson, C. (2015). Effect of low-level radioactive waste leachate on hydraulic conductivity of a geosynthetic clay liner. Proceedings, Geosynthetics Conference 2015, Portland, Oregon, Industrial Fabrics Association International, Roseville, MN, USA, pp. 236-244.

Tian, K., Benson, C. \& Likos, W. (2016a). Hydraulic conductivity of geosynthetic clay liners to low-level radioactive waste leachate. Journal of Geotechnical and Geoenvironmental Engineering, 142, No. 8, 1-12.

Tian, K., Likos, K. \& Benson, C. (2016b). Pore-scale imaging of polymer-modified bentonite in saline solutions. Proceedings, Geo-Chicago 2016, Chicago, IL, USA, GSP No. 271, ASCE, Reston, VA, USA, pp. 468-477.

Tian, K., Benson, C. \& Likos, W. (2017). Effect of anion ratio on the hydraulic conductivity of a bentonite-polymer geosynthetic clay liner. Proceedings, Geo-Frontiers 2017, Orlando, FL, USA, GSP No. 276, ASCE, Reston, VA, USA, pp. 180-189.

Trauger, R. \& Darlington, J. (2000). Next-Generation Geosynthetic Clay Liners for Improved Durability and Performance. TR-220. Colloid Environmental Technologies Company, Arlington Heights, IL, USA.

Yamanaka, S., Kanamaru, F. \& Kolzumi. (1974). Role of interlayer cations in the formation of acrylonitrile-montmorillonite complexes. The Journal of Physical Chemistry, 78, No. 1, 42-44.

The Editor welcomes discussion on all papers published in Geosynthetics International. Please email your contribution to discussion@geosynthetics-international.com by 15 February 2019. 